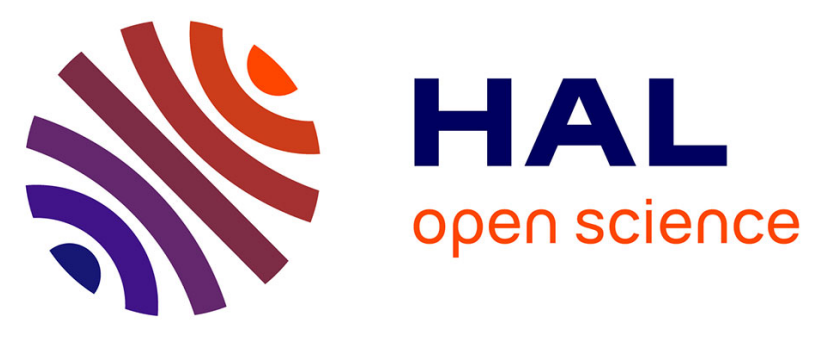

\title{
How Preschoolers Associate Power with Gender in Male-Female Interactions: A Cross-Cultural Investigation
}

\author{
Rawan Charafeddine, Imac Maria Zambrana, Benoit Triniol, Hugo Mercier, \\ Fabrice Clément, Laurence Kaufmann, Anne Reboul, Francisco Pons, \\ Jean-Baptiste van Der Henst
}

\section{To cite this version:}

Rawan Charafeddine, Imac Maria Zambrana, Benoit Triniol, Hugo Mercier, Fabrice Clément, et al.. How Preschoolers Associate Power with Gender in Male-Female Interactions: A Cross-Cultural Investigation. Sex Roles, 2020, 83 (7-8), pp.453 - 473. 10.1007/s11199-019-01116-x . hal-03039222

\section{HAL Id: hal-03039222 \\ https://cnrs.hal.science/hal-03039222}

Submitted on 9 Dec 2020

HAL is a multi-disciplinary open access archive for the deposit and dissemination of scientific research documents, whether they are published or not. The documents may come from teaching and research institutions in France or abroad, or from public or private research centers.
L'archive ouverte pluridisciplinaire HAL, est destinée au dépôt et à la diffusion de documents scientifiques de niveau recherche, publiés ou non, émanant des établissements d'enseignement et de recherche français ou étrangers, des laboratoires publics ou privés. 


\section{How Preschoolers Associate Power with}

Gender in Male-Female Interactions: A

Cross-Cultural Investigation

Rawan Charafeddine, Imac Maria Zambrana, Benoit Triniol, Hugo Mercier, Fabrice Clément, Laurence Kaufmann, Anne Reboul, et al.

\section{Sex Roles}

A Journal of Research

ISSN 0360-0025

Sex Roles

DOI 10.1007/s11199-019-01116-x 
Your article is protected by copyright and all rights are held exclusively by Springer Science+Business Media, LLC, part of Springer Nature. This e-offprint is for personal use only and shall not be self-archived in electronic repositories. If you wish to selfarchive your article, please use the accepted manuscript version for posting on your own website. You may further deposit the accepted manuscript version in any repository, provided it is only made publicly available 12 months after official publication or later and provided acknowledgement is given to the original source of publication and a link is inserted to the published article on Springer's website. The link must be accompanied by the following text: "The final publication is available at link.springer.com". 


\title{
How Preschoolers Associate Power with Gender in Male-Female Interactions: A Cross-Cultural Investigation
}

\author{
Rawan Charafeddine ${ }^{1}$ (D) Imac Maria Zambrana ${ }^{2}$ - Benoit Triniol ${ }^{1} \cdot$ Hugo Mercier $^{1}$ - Fabrice Clément ${ }^{3}$. \\ Laurence Kaufmann ${ }^{4} \cdot$ Anne Reboul $^{1} \cdot$ Francisco Pons $^{2} \cdot$ Jean-Baptiste Van der Henst ${ }^{1}$
}

(C) Springer Science+Business Media, LLC, part of Springer Nature 2020

\begin{abstract}
Interactions between males and females often display a power imbalance. Men tend to adopt more dominant physical postures, lead conversations more, and are more likely to impose their will on women than vice versa. Furthermore, social representations typically associate males with a higher power than females. However, little is known about how those representations emerge in early childhood. The present study investigated whether preschool children from different countries assign more power to males than to females in the context of mixed-gender interactions. In Experiments $1 \mathrm{a}(n=148)$ and $1 \mathrm{~b}(n=403)$, which implemented power through body postures, 4-6 year-old children from France, Lebanon, and Norway strongly associated power with a male character. Experiment $2(n=160)$ showed that although both French boys and girls identified themselves more with a dominant than with a subordinate posture, girls were less likely to do so in a mixed-gender context. In Experiment $3(n=213)$, which no longer used body postures, boys from Lebanon and France attributed more decision power and resource control to a male puppet than did girls. By investigating gender representations through interactions, the present study shows that children associate gender and power at an early age.
\end{abstract}

Keywords Power $\cdot$ Gender $\cdot$ Dominance $\cdot$ Preschoolers $\cdot$ Mixed-gender interactions $\cdot$ Cross-cultural comparisons

Because children grow up in a socially stratified world, they experience situations in which some individuals exert power and authority on others. Upon observing instances of such interactions, young children may appreciate that people who dominate and control others share common features. For instance, they will detect that adults often hold a position of

Electronic supplementary material The online version of this article (https://doi.org/10.1007/s11199-019-01116-x) contains supplementary material, which is available to authorized users.

Rawan Charafeddine

rawancharafeddine@gmail.com

Jean-Baptiste Van der Henst

vanderhenst@isc.cnrs.fr

1 Institut des Sciences Cognitives Marc Jeannerod, Laboratoire Langage Cerveau Cognition, UMR-5304, 67 Boulevard Pinel, 69500 Bron Cedex, France

2 University of Oslo, Oslo, Norway

3 Université de Neuchâtel, 2000 Neuchâtel, Switzerland

4 Lausanne University, 1015 Lausanne, Switzerland power when interacting with them. Similarly, as they begin to observe peer interactions, they might also learn that older children are likely to prevail over younger children in conflicts. Experimental work has shown that age and age-related features, such as body size, are robust cues used by young children and even infants to predict who is dominant in a social interaction (Charafeddine et al. 2015; Lourenco et al. 2016; Thomsen et al. 2011). Another recurrent aspect of the environment that correlates with power is gender. Although within the family and in the classroom the adults who exercise authority over children are more often women, in less benevolent contexts children are likely to be exposed to dyadic interactions between same-age individuals where men exercise power over women. The purpose of the present study is to determine whether early conceptions of male-female interactions carry a power asymmetry, that is, whether preschoolers consider that a dominant individual is more likely to be male or female.

Throughout history, human groups have consistently built gender categories on the basis of sexual morphological traits and have defined distinct masculine and feminine roles. Although gender roles vary considerably across societies 
and history, gender emerges as a social construct that distinguishes men from women on a hierarchical basis. Men have benefited from higher status than women, have controlled more of the public sphere, and have exercised power over women (Darmangeat 2009; Rosaldo et al. 1974; Whyte 1978). Most explanatory models that account for the origins of male domination pay particular attention to the sexual division of labor (SDL) in hunter-gatherer societies and describe it as the most ancient example of a status-relevant distinction between men and women. Broadly speaking, biological explanations argue that reproductive constraints prevent women from carrying out tasks that are described as risky or difficult and relegate them to the domestic sphere (Bird 1999; Murdock and Provost 1973). For other approaches, more than reproductive constraints, it is the exploitation and subjugation of women for the benefit of men that leads to multiple prohibitions imposed on women (Brightman 1996; Rosaldo et al. 1974; Tabet 1979).

Despite modern political efforts to promote gender equality and women empowerment in Western industrialized countries, a hierarchy persists (Ridgeway 2011). Women still occupy fewer prestigious jobs or leadership positions, control fewer resources than men, and spend more ime in domestic (i.e., unpaid and often devalued) work (Bianchi et al. 2000; Horne et al. 2018; Yavorsky et al. 2015). Asymmetries are also reflected through power dynamics that govern crossgender relationships. Statistics on femicide, rape, sexual harassment or genital mutilation are dramatic examples of men's power over women and their bodies (https://www. unfpa.org/).

At a less extreme but more widespread and systematic level, people recurrently perform gender inequality in their daily interactions (Goffman 1977; West and Zimmerman 1987). For example, in mixed-gender conversations, interruptions and turn-taking violations are more often made by males (Anderson and Leaper 1998), even in preschool years (Esposito 1979). Men are also more likely to communicate overt orders and imperatives as well as speak in an assertive manner, whereas women are more likely to engage in indirect requests and in polite and tentative language (Anderson and Leaper 1998; Lakoff 1973). Nonverbal behaviors also show some gender differences relevant to power. Men tend to adopt more open and expanded body postures and speak louder than women (Cashdan 1998; Hall et al. 2005; Henley 1977). They also demonstrate dominant gaze behavior (Dovidio et al. 1988; Ridgeway 2013), that is, men are more likely than women to display direct gaze while speaking and divert gaze while listening rather than the reverse (dominant gaze ratio; Dovidio et al. 1988). All such behaviors obviously might be reinforced by gender stereotypes held by adults and transmitted to children, leading to considering women as less competent and agentic than men (Fiske et al. 2007; Fiske et al. 2002). Gender stereotypes also lead to judging dominant behavior and leadership more negatively when adopted by women than by men (Eagly et al. 1992).

In addition to asymmetric male-female relationships and gender stereotypes, individual physical traits related to sex can influence the perception of who dominates in an interaction. In most primate species including humans, males are taller, have lower voices, more muscular bodies, and more dominant faces. Within each sex, these traits correlate with social status and the outcome of conflicting interactions, and people often use these traits to predict who is dominant (Lukaszewski et al. 2016; Puts et al. 2006; Todorov et al. 2015; Toscano et al. 2014). Hence, children are likely to be exposed to a wide set of stimuli of male-female differences, including daily interactions, adult stereotypes, and morphological features that are relevant to assign more power to males.

\section{Understanding of Social Hierarchies in Early Ages}

Recently, growing evidence has shown that preschoolers and even infants exhibit a fine-grained understanding of hierarchical relationships. First, children's identification of hierarchy relies on the observation of dynamic interactions. Three- to 4year-old children judge that individuals who impose their preference on other individuals or who deny permission to use resources are the boss or are in charge, and children five years and older base their power judgments on even more subtle interactions, such as setting norms for others or being imitated (Charafeddine et al. 2015; Gülgöz and Gelman 2017; Over and Carpenter 2015).

Furthermore, children rely on a variety of physical and nonphysical cues to predict who is dominant. For instance, erect body postures, being endowed with more resources, or being older are understood as marks of power (Brey and Shutts 2015; Charafeddine et al. 2015; Gülgöz and Gelman 2017; Terrizzi et al. 2018). Moreover, before the age of one, infants expect larger agents or agents with more allies to prevail in conflicts (Pun et al. 2016; Thomsen et al. 2011). It is also important to note that, like adults, preschoolers are sensitive to physical dominance cues that correlate with differences between males and females. They thus consider that individuals with more masculine faces, that is, those exhibiting larger jaws, wider chin, and thicker brows, are stronger and are more likely to be in charge than people with less masculine faces (Cogsdill et al. 2014; Keating and Bai 1986; Terrizzi et al. 2018).

Another key aspect of children's ability to represent social hierarchies lies in the inferences they draw. Studies using preferential looking technique suggest that fifteen-month infants tend to generalize a dominance relationship between two agents, represented by geometrical figures, from one situation 
to another (Mascaro and Csibra 2012) and that 10-13-monthold infants draw transitive inferences on the basis of dyadic relations between animal puppets (Gazes et al. 2017). In preschool years, children also associate different dimensions of social hierarchy. When 3-5-year-olds are presented with a dominant individual who gives orders and tells another subordinate individual what to do, they expect the dominant person to have more resources and to win a competitive game against the subordinate (Charafeddine et al. 2015). A study by Enright et al. (2017) also suggests that 17-month-old infants infer dominance from asymmetry in resources. Moreover, preschoolers expect the dominant individual to be better informed than a subordinate individual (Bernard et al. 2016; Castelain et al. 2016). In the current study, we will examine whether inferences children make from power interactions also extend to gender, that is, whether they expect that the powerful individual is more likely to be a girl or a boy in mixed-gender interactions.

\section{Early Conceptualization of a Gender Hierarchy}

Among the categories that children use to carve up the social world, gender is one of the most prominent (Bussey and Bandura 1999; Fagot et al. 2012; Kinzler et al. 2010; Martin and Halverson Jr 1981; Martin et al. 2002). However, most studies dedicated to children's representations of gender have mainly investigated conceptualizations of individual characteristics related to men and women and did not directly focus on relational dynamics, such as the imbalance of power between genders.

Some research addressed gender inequality in the positions held by men and women in society. For instance, in a study conducted by Liben et al. (2001), 6-8-year-old and 11-12year-old children rated the status of familiar jobs, which were culturally masculine or feminine, and the status of unknown fictitious jobs held by women or by men. For familiar jobs, both age groups judged that masculine jobs were higher in status than feminine jobs, whereas only the older group generalized this asymmetry to unknown jobs. In a related study (Weisgram et al. 2010), which involved children (5-10 yearsold), adolescents (11-17 years-olds) and adults, participants assigned higher scores of remuneration and power (i.e., making rules for others) to masculine jobs than to feminine jobs, with a developmental pattern indicating that this difference was greater for adults than for adolescents and greater for adolescents than for children. Similarly, Neff et al. (2007, Study 2) interviewed 7-15-year-old participants about gender asymmetries in society with questions related to status and power, such as "In general, who do you think has more power to make important decisions and tell other people what to do, men or women or do both have the same amount of power?"
Whereas the youngest children perceived gender equality in power and status, the oldest participants attributed a higher rank to men. However, in those studies, the weaker perception of gender inequality observed for younger children might result from a more limited experience with gender imbalance in a societal context, which requires considering women and men, power and status, as abstract societal entities. Younger children may have clearer expectations of gender asymmetries in situations involving concrete and observable interactions, in which an individual gives orders to another individual, prevails in conflicts, or monopolizes more resource.

Also relevant to the current study are psychological traits that children associate with females and males. Past research has shown that preschoolers have knowledge of gender roles and adult gender stereotypes (Cowan and Hoffman 1986; Fagot et al. 1992; Kuhn et al. 1978; Leinbach et al. 1997; Picariello et al. 1990; Williams et al. 1975), which could influence their representation of power in mixed-gender interactions. For example, preschoolers tend to associate fear, weakness, and softness with female characters and anger, strength, and hardness with male characters (Birnbaum and Chemelski 1984; Birnbaum et al. 1980; Cowan and Hoffman 1986). Preschoolers also expect unknown female characters to adopt more pro-social behaviors than male characters (Clément et al. 2014). Finally, children also hold beliefs on aggressive behavior that differ according to the gender of the aggressor. In particular, when preschoolers are asked to describe how boys and girls are likely to harm another child, they tend to see boys as the perpetrators of physical aggression (e.g., hitting, throwing things at someone) and see girls as the perpetrators of relational aggression (e.g., denying friendship, not playing with another child) (Giles and Heyman 2005). Such representations are consistent with actual field observations on gendered styles of aggression (Crick et al. 1997; Crick and Grotpeter 1995; Ostrov and Keating 2004).

Children's conceptions of a gender hierarchy have also been examined in the context of status differences between social groups (Mandalaywala et al. 2019; Olson et al. 2012). This research compares how children from preschool years make sense of race and gender as cues to group-based hierarchies, and it uses wealth-to-group matching tasks to measure perception of status. Whereas children match the stereotypically high-status race group (i.e., faces of White people) with a high level of wealth (e.g., high-value houses), as compared to the lower status racial group (i.e., faces of Black people), they do not do so for gender. In particular, they did not match more male targets as compared to female targets with higher value resources. Rather, children sometimes show a slight tendency to associate their own gender with higher value goods (Olson et al. 2012). However, when the wealth asymmetry more directly involves competition for resources relevant to children (e.g., having lots of toys and new clothes, always getting to pick the tasks that 
everyone else plays at recess and the snacks that everyone else eats at snack time), preschoolers assign a higher status to male targets (Mandalaywala et al., 2019).

The prior research shows asymmetries in children's conceptions of male and female categories, but it does not directly address the representation of mixed-gender interactions and power relations. Understanding how children conceptualize mixed-gender relationships with respect to power is important not only for research on cognitive development but also for understanding the perpetuation of gender inequalities and their justifications in societies. If young children consider boys to be more likely to dominate girls than the other way around, they may act in conformity with such an asymmetry or believe that it is appropriate.

\section{The Current Experiments}

The present studies examine four issues. The first relates to preschoolers' expectations about the gender of the individual who displays more or less power in a dyadic interaction. Because in mixed-gender interactions involving adults, men are more likely to dominate women (Carli 1999), and because preschoolers are good at understanding power relationships from interactions and from physical features, they might associate power with male individuals. An important question is the developmental pathway of this association. Although past research has shown that even infants use differences between individuals to infer who is dominant in an interaction, some asymmetries relevant to power are not always understood by young children. Indeed, although 3-4-year-old children used resource control, goal achievement, age, and denying permission as cues to power, it is only between 5 and 7 years of age that children consider an individual who sets norms for others, or who is imitated by others, to hold a powerful position (Gülgöz and Gelman 2017; Over and Carpenter 2015).

The second issue is the potential influence of participants' gender. There is converging evidence that children view their own gender and members of their gender categories positively. Observations of young children in daycare facilities showed that shortly before their third birthday, children affiliate more with same-gender peers (Fishbein and Imai 1993; La Freniere et al. 1984; Maccoby and Jacklin 1987). When preschoolers are explicitly asked to rank their peers according to whom they prefer, they tend to attribute higher scores to samegender children (Hayden-Thomson et al. 1987; Kuhn et al. 1978; Sebanc et al. 2003). Moreover, preschoolers tend to align their preferences for novel objects with those of samegender peers (Shutts et al. 2009) and are more likely to endorse the testimony of same-gender informants (Ma and Woolley 2013; Terrier et al. 2016). Children also show a bias for their own gender in implicit attitude test (Dunham et al.
2016), and they think that their own gender is judged positively by other people (Halim et al. 2013).

In addition to the own-gender bias, preschoolers show positive attitudes toward dominant individuals (Hawley 1999). They trust the testimony of a dominant individual more than that of a subordinate (Bernard et al. 2016; Castelain et al. 2016), and 3-4-year-olds distribute resources in ways that benefit dominant over subordinate individuals (Charafeddine et al. 2016). Hence, viewing one's own gender positively may modulate the association between being male and power. That is, girls may be less likely to consider a dominant individual to be a male than boys. A strong version of this hypothesis would be that girls consider that a dominant character is a female to the same extent as boys consider that a dominant character is a male.

The third issue is how self-perception interacts with the male-power association. Preschoolers tend to view their own dominance rank as high (Mandalaywala et al. 2019; Omark and Edelman 1975; Sluckin and Smith 1977; Strayer et al. 1978), and in a western culture such as France, they tend to identify themselves more with the dominant than with the subordinate figure (Charafeddine et al. 2019). A selfenhancement bias could thus override, or at least diminish, the male-power association in girls. That is, boys may see themselves as dominants when they imagine themselves interacting with girls, but girls may also see themselves as dominants when they imagine interacting with boys.

The fourth issue concerns the influence of the cultural context on the male-power association. Research has shown that culture modulates the content of gender stereotypes (Williams and Best 1982) and that the social environment can affect preschoolers' attitudes toward gender (Shutts et al. 2017). In particular, in their study, which involved 25 cultures, Williams and Best (1982) observed a greater differentiation of stereotypes in Muslim countries, especially in Pakistan, than in nonMuslim countries. Other studies have also reported more pronounced stereotypes among Italian than Dutch children (Zammuner 1982) and more pronounced male stereotypes among South African than among U.S. children (Albert and Porter 1986). One may anticipate that the male-power association is stronger or emerges earlier in countries where gender inequalities are more prevalent. To examine this issue, Experiment 1 involved French, Lebanese, and Norwegian participants and Experiment 3 compared French and Lebanese participants.

The current work follows a methodology typical of developmental research on gender stereotypes. It consists of presenting participants with a specific behavior and asking them to guess whether this behavior is more likely to be performed by a girl or a boy (Kuhn et al. 1978; Williams et al. 1975). The experimental procedure in Experiment 1 obtained ethical approval from the Norwegian ministry of education (Norwegian Centre for Research Data, \#30095). The procedures in 
Experiments 1, 2, and 3 were approved by the French ministry of education (Inspection Académique and Coordination Académique Recherche-Développement Innovation et Expérimentation). In the absence of a national ethical board in Lebanon, the Lebanese ministry of education and higher education gave an approval in principle to conduct the experiments.

\section{Experiment 1a}

A combination of nonverbal (i.e., dominance and subordination physical postures) and verbal cues (statements expressing power) were used to convey a power asymmetry between two nongendered individuals. Then, participants had to guess the gender of the dominant and the gender of the subordinate. Facial expressions, body postures, and gestures are common indicators of dominance, such as pointing, touching, staring, frowning or maintaining an erect posture (Hall et al. 2005; Henley 1977; Weisfeld and Beresford 1982). Adults quickly use such features to determine power positions (Hall et al. 2005; Schmid-Mast and Hall 2004). However, the extent to which a power asymmetry is perceived through postures is modulated by the gender of individuals adopting such postures. Henley and her colleagues found that when women display dominance gestures (e.g., pointing at another individual, invading space) toward men, such gestures were less often interpreted as signaling dominance than when they were displayed by men toward women (Henley 1977; Henley and Harmon 1985). Experiments $1 \mathrm{a}$ and $1 \mathrm{~b}$ examine whether a similar effect holds for children.

Developmental research has shown that preschoolers are able to infer power from nonverbal features. For instance, Keating and Bai (1986) found that children tend to associate nonsmiling and lowered-brow faces with the dominant position (see also, Cogsdill et al. 2014; Terrizzi et al. 2018). Similar results were obtained with body postures and gestures (Charafeddine et al. 2015; Charafeddine et al. 2019). Children saw a picture with two characters displaying either dominance or subordination features: the dominant character had their head up and an erect body and displayed a pointing gesture (Henley and Harmon 1985) at the subordinate character who had their head down and who exhibited a constriction posture. Charafeddine et al. (2015) found that 3-5-year-old children judge that the former character was the dominant, and Charafeddine et al. (2019) reported that this tendency was stronger for 5- than for 3-year-old children. The ability to attribute power to body postures has also been reported by Brey and Shutts (2015) and Terrizzi et al. (2018), who show that older preschoolers are more sensitive to these cues than younger preschoolers. In Experiments $1 \mathrm{a}$ and $1 \mathrm{~b}$, we use a similar dominance-subordination interaction picture with nongendered characters as in Charafeddine et al. (2015,
2019). Here, participants first had to decide who was dominant and who was the subordinate and subsequently had to guess who was the girl and who was the boy.

\section{Method}

\section{Participants}

Initially 149 French preschoolers participated in this experiment. They were tested in two public nursery schools located in middle SES neighborhoods in the city of Lyon. Parental consent was obtained for each child. One child was excluded from the analysis for failing to answer the gender-attribution questions. The final set of participants included 148 children $\left(M_{\text {age }}=56.4\right.$ mo., $\left.S D=9.03\right)$ from three age groups: 34 year-olds $\left(M_{\text {age }}=42.9\right.$ mo., $S D=3.56 ; 12$ girls and 22 boys $)$, 52 4-year-olds $\left(M_{\text {age }}=55.3\right.$ mo., $S D=3.18 ; 25$ girls and 27 boys $)$, and 62 5-year-olds $\left(M_{\text {age }}=64.7\right.$ mo., $S D=3.28 ; 31$ girls and 31 boys).

\section{Materials and procedure}

Three female experimenters interviewed the participants; all of them followed the same standardized procedure. As in studies by Charafeddine et al. $(2015,2019)$, the first part of the task consisted of deciding who was dominant and subordinate by answering two comprehension questions. Children saw a drawing of two nongendered characters interacting with each other, one displaying a dominance posture and the other displaying a subordination posture (see Fig. 1; the original color version of this figure is available in the online supplement). They were told that one character was saying: "You have to do everything I say! Do what I want!" [Tu dois faire tout ce que je dis! Fais comme je veux!] (power statement) and the other was replying: "Ok! I will do what you want" [D'accord je fais ce que tu veux] (obedience statement). Children then had to match postures with each statement. The spatial positions (left vs. right) of the characters were counterbalanced across participants. When participants
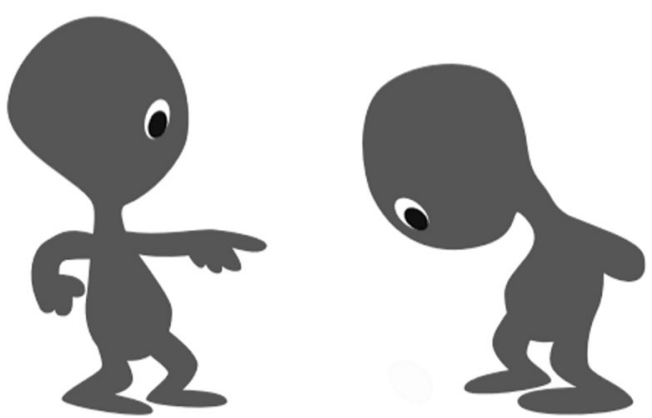

Fig. 1 Two characters displaying postures of dominance and subordination (see the online supplement for the original colored version of the picture) 
matched the dominance posture with the power statement and the subordination posture with the subordination statement, their answer was considered as correct. In the second part of the task, participants were told that the picture actually depicted a girl and a boy and were asked to indicate who was who.

The specific instructions were as follows:

Look! You see? There are two children. Do you see them? One of the children tells the other: "You must do everything I say! Do whatever I want!" And the other child is saying: "OK! I will do what you want."

These instructions were followed by two comprehension questions (with their order counterbalanced): "Who is saying 'Do what I want?", "Who is saying 'OK! I will do what you want?" The procedure then continued with the statement, "In fact, in this picture there is a girl and a boy," followed by two gender attribution questions (with their order counterbalanced): "Could you tell me who is the girl?"; "And who is the boy?"

\section{Results}

All through the present paper, the reported binomial tests are two-tailed and compare the relevant rates to chance (50\%).

\section{Comprehension questions}

Fully 124 of $148(83.78 \%)$ correctly matched the erect body posture with the power statement and the subordinate posture with the obedience statement $(p<.001,95 \%$ CI [76.84, $89.32]$ ). There was no significant effect of age group (3year-olds: $82.35 \%$, 4-year-olds: $82.69 \%$; 5-year-olds: $85.48 \%), \chi^{2}(2, n=148)=.23, p=.892$ or participants' gender (girls: $85.29 \%$ and boys: $82.50 \%), \chi^{2}(1, n=148)=.21$, $p=.646$.

\section{Gender assignment}

A logistic regression was run on all the data to assess the effects of age, gender of the participants, and comprehension questions (incorrect (0), correct (1)) on gender assignment. The gender associated with the dominant figure was coded in a binary manner: female (0) and male (1). The Chi-square test on the produced model revealed that the answer to the comprehension question was the only significant factor $(p<.001$; Akaike Information Criterion [AIC] $=176.35)$. Children who incorrectly answered the comprehension questions were at chance: $37.5 \%$ associated the erect body posture with a male character $(p=.307,95 \%$ CI $[40.59,81.2])$. In contrast, $75 \%$ of the children who correctly answered those questions considered that the dominant character was a boy $(p<.001,95 \%$ CI $[66.42,82.33])$. The difference between the two types of children was significant $(37.5 \%$ vs. $75 \%), \chi^{2}(1$, $n=148)=13.2, p<.001$. Children's age was not significant in the model $(p=.070)$.

Furthermore, we analyzed gender assignment among the 124 children who correctly answered the first two comprehension questions. The male-power association was significantly above chance for the 4-year-old group $(74.42 \% ; p=.002$, $95 \%$ CI $[58.83,86.48])$ and the 5-year-old group $(83.02 \%$; $p<.001,95 \%$ CI $[70.2,91.93])$, but not for the 3 -year-old group $(60.71 \%, p=.345,95 \%$ CI [40.58, 78.49]). However, the comparison between age groups was still not significant, $\chi^{2}(2, n=124)=4.87, p=.087$. Finally, children's gender was not a significant factor $(p=.912)$. Among the 124 children who correctly answered the comprehension questions, the male-power association was above chance level for both girls (77.59\%; $p<.001,95 \%$ CI $[64.73,87.49])$ and boys $(72.73 \%$; $p<.001,95 \%$ CI $[60.36,82.97])$. The difference between male and female participants was not significant, $\chi^{2}(1, n=$ $124)=.39, p=.533$.

\section{Discussion}

In line with earlier studies, preschoolers correctly interpreted dominance postures (Brey and Shutts 2015; Charafeddine et al. 2015, 2019; Keating and Bai 1986; Terrizzi et al. 2018). More importantly, the results indicated that 4 - and 5 year-old children expected the dominant character to be a male in the context of mixed-gender interactions. This finding echoes results with adults showing that when dominance gestures are performed by men, they are more likely to be interpreted as conveying dominance than when performed by women (Henley and Harmon 1985). However, the male-power association was not found among 3-year-old children. This nonfinding suggests that this association emerges later than associations linking power to other dimensions such as age, resources, physical superiority or getting one's way (Charafeddine et al. 2015; Gülgöz and Gelman 2017). The hypothesis of an influence of children's gender was not supported. Girls were not biased toward their own gender and exhibited the same male-power association as did boys. Although participants' gender had no effect, another factor that might modulate the male-power association is culture. Experiment $1 \mathrm{~b}$ examines this factor by comparing Lebanese and Norwegian children on the same task.

\section{Experiment 1b}

Gender inequality largely differs across cultures and nations. In environments where the level of gender inequality is relatively 
low, children might perceive gender relationships as less unequal than in countries where it is higher. Two well-known indexes provide worldwide measures of gender inequality: The Global Gender Gap Index (GGGI), developed by the World Economic Forum, which measures the gender gap in the areas of politics, economics, education and health, and the Gender Inequality Index (GII), established by the United Nations Development Program, which focuses on reproductive health, empowerment, and the labor market. The GGGI indicates that France's rank ranged from 57th to 15th (median rank: 17) over the 2012-2016 period, and the GII indicates that France's rank ranged from 19th to 9th (median rank: 12.5) over the 2012-2015 period. Using the same procedure as Experiment 1a, Experiment $1 \mathrm{~b}$ examines the male-power association with preschool children from two countries that differ in terms of gender inequality-Norway and Lebanon.

Norwegian policies largely promote gender equality not only in welfare and job occupations but also in the area of education, as shown by government guidelines in kindergarten (Rossholt 2003) and mandatory interventions in middle and high school (Parker et al. 2009Over 2012-2016, Norway was ranked 2nd or 3rd according to the GGGI and ranged from the 9th to 5th rank according to the GII over the 2012-2015 period. In contrast, in Lebanon, legal and social discriminations based on gender are much more common (Human Rights Watch 2015; Mansour and Karam 2012). Over 2012-2016, Lebanon's rank on the GGGI ranged from 138th to 120th, and over 2012-2015, Lebanon's rank on the GII ranged from 83rd to 78th.

In Experiment 1b, we expected the male-power association to be lower among Norwegian than among Lebanese children. Moreover, the developmental course of the male-power association might depend on the culture in which the child is reared. If a cultural environment allows for recurrent manifestations of male dominance, then children might grasp the male-power association earlier. In addition, it is known that children become more egalitarian with age, especially after five years of age (Fehr et al. 2008; Lane and Coon 1972; LoBue et al. 2011; Rochat et al. 2009). In societies where gender equality is promoted, older children could thus be more likely to integrate gender into their representation of social equality than younger children. To examine this issue, Experiment $1 \mathrm{~b}$ included not only 3-, 4- and 5-year-old children but also 6-7-year-old children.

\section{Method}

\section{Participants}

Participants were 417 Norwegian and Lebanese children. They were tested in their schools or day care facilities after written consent was collected from their parents. In Norway, 152 children participated in the experiment, but 5 children from the youngest age group were excluded from the analysis for failing to answer the gender-attribution questions. The final Norwegian sample was composed of 147 children $\left(M_{\text {age }}=\right.$ 62.8 mo., $S D=13.24,69$ girls and 78 boys) and was divided into four age groups: 223 -year-olds $\left(M_{\text {age }}=43.1 \mathrm{mo}\right.$., $S D=$ 13.24; 11 girls and 11 boys), 48 -year-olds ( $M_{\text {age }}=54.9$ mo., $S D=3.43 ; 19$ girls and 29 boys $), 415$-year-olds $\left(M_{\text {age }}=66.9\right.$ mo., $S D=3.3,17$; girls and 24 boys) and 36 6-7-year-olds (there were only 37 -year-olds; $M_{\text {age }}=80.7 \mathrm{mo} ., S D=4.12 ; 22$ girls and 14 boys). Children came from six childcare centers and one school. A plurality (41\%) of the children went to school or kindergarten located in middle-class neighborhoods. One childcare center was private and thus comprised children from more prosperous families ( $46 \%$ of the participants), and $13 \%$ of the participants attended a childcare center located in a low-income neighborhood.

In Lebanon, 263 children participated in the experiment, but seven children were excluded from the analysis for failing to answer the gender-attribution questions. The final Lebanese sample included 256 children aged 3 to 6 years-old divided into four age groups ( $M_{\text {age }}=60.29 \mathrm{mo}$., $S D=14.68 ; 126$ girls and 130 boys): 803 -year-olds ( $M_{\text {age }}=43.1$ mo., $S D=3.29 ; 40$ girls and 40 boys), 63 4-year-olds ( $M_{\text {age }}=56.2$ mo., $S D=$ 3.71; 26 girls and 37 boys), 565 -year-olds $\left(M_{\text {age }}=69\right.$ mo., $S D=3.81 ; 28$ girls and 28 boys), and 576 -year-olds $\left(M_{\text {age }}=\right.$ 80.4 mo., $S D=3.19$, 33; girls and 24 boys). Participants attended three private schools in Beirut and one in South Lebanon. Two of the Beirut schools were located in predominantly Christian neighborhoods: one of these schools had tuition fees in the high average of Lebanese schools (23\% of the participants), whereas the other had low tuition fees ( $24 \%$ of the participants). The third Beirut school was located in a mainly Muslim (Sunni) neighborhood and had tuition fees in the high average (38\% of the participants). The last school in south Lebanon was located in a popular Muslim (Shiite) area and had average tuition fees (15\% of the participants). The proportion of girls did not significantly differ across the two groups (46.94\% in the Norwegian group and $49.21 \%$ in the Lebanese group), $\chi^{2}(1, n=403)=.19, p=.654$.

\section{Materials and procedure}

The material and procedure were the same as in Experiment 1a. The dialogue was translated into Norwegian and Arabic. Back-translation into French yielded minimal or no divergence from the original text. One Norwegian and one Lebanese female experimenters conducted the experiment in their respective countries using a common standardized experimental procedure.

\section{Results}

A total of 364 of $403(90.32 \%)$ children correctly answered the comprehension questions $(p<.001,95 \% \mathrm{CI}[87,93.03])$. 
No significant effect of gender (girls: $89.74 \%$ and boys: $90.87 \%), \chi^{2}(1, n=301)=.14, p=.703$, or culture was found (Norway: 93.2\% and Lebanon: $88.67 \%), \chi^{2}(1, n=301)=$ $2.19, p=.139$, but there was a significant effect of age, $\chi^{2}$ $(3, n=403)=25.02, p<.001$. The partition of the Chisquare test (Agresti 2002) shows that the 3-year-old group significantly differs from the other three groups, $\chi^{2}(1, n=$ $403)=22.09, p<.001$, whereas the 4-year-old, 5 -year-old and 6 -year-old groups did not significantly differ from each other, $\chi^{2}(2, n=301)=4.53, p=.104$. The proportions of correct associations between postures and statements were significantly above chance level for all four age classes. Specifically, the proportions are as follows: $78.43 \%$ of the 3year-olds $(p<.001,95 \% \mathrm{CI}=[69.18,85.96]), 90.99 \%$ of the 4 -year-olds $(p<.001,95 \%$ CI $[84.05,95.59]), 94.85 \%$ of the 5 -year-olds $(p<.001,95 \%$ CI $[88.37,98.3])$, and $97.85 \%$ of the 6-year-olds ( $p<.001,95 \%$ CI $[92.44,97.74])$.

To assess the specific ways in which age, gender, and culture of the children affect the results, a logistic regression was first run on all the data. For Experiment 1a, the gender associated with the dominant figure was coded in a binary manner: female (0) and male (1). The following factors were included in the regression: participant's country, age in months, gender, and the answer to the comprehension questions (incorrect (0) or correct (1)). An age-by-culture interaction was also included in the model. The Chi-square test on the produced model revealed that answers to the comprehension questions $(p=.008)$ and age $(p=.004)$ are the only two significant factors (Akaike Information Criterion $[\mathrm{AIC}]=497.36$ ). Children who erred on the comprehension question assigned the male character to the erect body posture at rates that did not significantly differ from chance level $(48.72 \% ; p=.937,95 \%$ CI $[32.42,65.22])$. Conversely, $70.60 \%$ of the children who correctly understood the postures assigned the male character to the erect body posture, a rate that was significantly above chance level $(p<.001,95 \%$ CI $[65.62,75.24])$. Because the comprehension of postures significantly affected the association between gender and dominance, $\chi^{2}(1, n=403)=7.82$, $p=.005$, all supplementary analyses were performed on the subset of 364 children who gave a correct answer to the comprehension questions.

Among the children who correctly answered the comprehension question, gender attribution was significantly affected by age group, $\chi^{2}(3, n=364)=8.38, p=.039$. Partition of the Chi-square shows a significant difference between the 3-yearold children and all the other children, $\chi^{2}(1, n=364)=5.55$, $p=.018$, but no effect of age for the three age groups between 4 and 6 years, $\chi^{2}(2, n=284)=3.014, p=.221$. Specifically, whereas the male-power association was not significant among the 3-year-old children $(60 \%, p=.093,95 \%$ CI $[48.44,70.8]$ ), it was significant in the other three groups (4year-olds: $68.32 \%, p<.001,95 \%$ CI [68.3,77.22]; 5- yearolds: $79.34 \%, p<.001,95 \%$ CI $[69.64,87.08]$, and 6- year- olds: $73.63 \%, p<.001,95 \%$ CI $[63.34,82.31])$. Contrary to our expectations, the model did not yield an effect of participants' gender $(p=.599)$, culture $(p=.333)$, or an interaction between age and culture $(p=.409)$.

Among children who correctly answered the comprehension questions, girls $(69.71 \%, p<.001,95 \%$ CI $[62.33$, $66,42])$ were as likely as boys $(71.43 \%, p<.001,95 \%$ CI $[64.42,77.75])$ to assign the male character to the dominant posture, $\chi^{2}(1, n=364)=.13, p=.719$. Similarly, Norwegians $(71.53 \%, p<.001,95 \%$ CI $[63.19,78.91])$ were as likely as Lebanese $(70.04 \%, p<.001,95 \%$ CI $[63.63,75.92])$ to make this association, $\chi^{2}(1, n=364)=.09, p=.763$. There was no significant male-power association among the 3 -year-old children from the two countries (Norway: $52.63 \%, p=.824,95 \%$ CI $[28.86,75.55]$ and Lebanon: $62.29 \%, p=.0721,95 \%$ CI [48.96, 74.39]. In both countries, the other age groups were significantly above chance level (all $p s<.035$ ).

\section{Discussion}

As in Experiment 1a, 4- to 6-year-old children, but not 3-yearolds, associated the dominant posture with the male character. However, in the current experiment, 3-year-olds were less likely to infer dominance from postures than older children. Although this developmental effect was not observed in Experiment 1a or in an earlier study using the same stimuli (Charafeddine et al. 2015), it was found in another study using the same stimuli (Charafeddine et al. 2019), as well as in a study using different stimuli (Terrizzi et al. 2018). In particular, Terrizzi et al. (2018) found that 3-year-old children were above chance when using postural information to judge strength ("Who is stronger?") but not when they had to judge authority ("Who is in charge?"). Moreover, whereas 4- and 5year-old children were good at matching powerful faces with powerful postures, 3-year-old children responded at a chance level (Terrizzi et al. 2018). In Experiments 1a and 1b, children were more likely to assign the male character to the dominant posture when they first correctly matched a dominance posture with a dominance statement. Given that 3-year-olds were less aware that postures can convey power than older children, they might be less likely to use dominance postures to assess the gender of the powerful. In other words, their understanding of postures might not be mature enough to allow inferences from power to gender. Although in Experiment 1a, French 3-year-olds performed as well as older children in the comprehension questions, it might still be the case that their understanding of dominance postures is weaker than older children's on other measures.

Second, contrary to our expectations, the male-power association did not vary across cultures. Explicit cultural norms, such as gender equality prevalent in Norway, did not prevent our participants from thinking that dominants were more likely to be boys. Hence, although Norway and Lebanon differ 
with respect to women's empowerment, such cultural differences may not be strong enough to modify the belief in male dominance. This may be due to a discrepancy between the official politics of gender equality and the reality of asymmetric mixed-gender relationships to which young children are exposed in their environment. However, other cultures, age groups, and other dominance asymmetries may need to be explored further. Measures of gender inequality considered here, namely, the GGGI and the GII, do not explicitly take into account situations in which gender inequality manifests itself through situations in which one individual gives orders and tells someone what to do to another individual. In Experiment 3, we use resource asymmetry as another expression of dominance, which is more in line with the areas evaluated by the GGGI and the GII.

Another striking feature of our results is that in both experiments, the girls' answers did not significantly differ from the boys' answers, which suggests that the girls and boys perceived gender inequalities in similar ways. This result does not support the hypothesis that the positive viewing of their own gender would lead girls to consider that a dominant individual is more likely to be a girl. It could even be possible that girls might judge other girls who are adopting a dominant behavior more negatively because such behavior would violate gender norms associated with females. In keeping with this interpretation, Sebanc et al. (2003) found that, in the context of a competitive task, high-ranking preschool girls who controlled more resources and who adopted a dominant behavior in doing so (e.g., issuing more commands) were less accepted by peers, particularly by girls, than lowerranking girls, whereas high-ranking boys were more accepted by peers. In Experiments $1 \mathrm{a}$ and $1 \mathrm{~b}$, a positive gender bias thus may have yielded the same patterns of response among boys and girls, but for different reasons.

Although girls may not see their own gender category as the dominant one, research shows that they do, however, hold high opinions, as do boys, of their own dominance status. This pattern was originally found in early work on dominance perception in which participants had to compare themselves with each of their peers for toughness (e.g., "Who is the toughest? You or Kevin?"; Edelman and Omark 1973; Omark and Edelman 1975; Sluckin and Smith 1977; Strayer et al. 1978). Preschoolers largely disagreed with their peers because they frequently answered that the tougher individual was themselves and thus tended to overrate their status. More recently, using a rope task that measures subjective status through power and wealth, Mandalaywala et al. (2019) found that boys and girls, from 3.5- to 6.5-years-old, viewed their own status as particularly elevated because they scored almost at ceiling on this task.

Charafeddine et al. (2019) also observed evidence of such optimistic views in a self-identification task. They presented to French and Japanese preschoolers the same picture as in Experiments 1 and 2 and found that French preschoolers, but not Japanese, were more likely to identify with the dominant character, with no difference between girls and boys. In that experiment, the gender of the other character on the picture was not specified so that participants were not lead to imagine a dominance interaction between themselves and a different-gender child. However, in studies in which school-age children had to compare themselves for toughness, girl-boy dyads elicited a relatively high level of agreement among children (1st to 4 th grade). The boy tended to be recognized as the tougher individual by both the boy and the girl of the dyad, whereas same-gender dyads produced a lower level of agreement (Edelman and Omark 1973; Omark and Edelman 1975). Experiment 2 addresses this issue with preschoolers and through the same power relation presented in Experiments $1 \mathrm{a}$ and $1 \mathrm{~b}$. It thus investigates whether the male-power association observed among boys and girls affects their perceptions of their own power status.

\section{Experiment 2}

In Experiment 2, participants saw the same picture as in Experiments $1 \mathrm{a}$ and $1 \mathrm{~b}$, but instead of assigning a gender to each character, they had to identify themselves with one of the two characters and were informed that the other character was either a girl or a boy. Hence, the other character could be of the same gender as themselves (same-gender condition) or could be of a different gender (different-gender condition). In the same-gender condition, we predicted that girls and boys would identify more with the dominant character, and we did not expect a difference between girls and boys because both previously exhibited a similar tendency in an analogous sample (Charafeddine et al. 2019).

In the different-gender conditions, three predictions from three alternative hypotheses were tested. First, if the selfenhancement bias trumps the male-power association, then both girls and boys would identify with the dominant character and would do so to a similar extent. Second, if the malepower association trumps the self-enhancement bias, then boys would identify with the dominant character to the same extent as girls would identify with the subordinate one. Third, if both factors operate, boys would be more likely than girls to identify with the dominant character, but girls would identify with the subordinate to a lesser extent than boys would identify with the dominant one. Given that 3-year-old children did not associate power with a male character in Experiments 1a and $1 \mathrm{~b}$ and given that they are less likely to infer power from postures, we included only 4- and 5-year-old children in Experiment 2. 


\section{Method}

\section{Participants}

Fully 160 French children participated in this experiment $\left(M_{\text {age }}=60.9\right.$ mo., $\left.S D=6.47\right)$ and were divided into two age groups: 4-year-olds (80 children, $M_{\text {age }}=55.3$ mo., $S D=3$ ) and 5-year-olds ( 80 children, $M_{\text {age }}=66.6 \mathrm{mo}$., $S D=3.28$ ). The 4-year-old group was composed of 40 girls $\left(M_{\text {age }}=54.4\right.$ mo., $S D=3.23)$ and 40 boys $\left(M_{\text {age }}=56.1\right.$ mo., $\left.S D=2.42\right)$, and the 5-year-old group was composed of 40 girls $\left(M_{\text {age }}=\right.$ 66.3 mo., $S D=2.98)$ and 40 boys $\left(M_{\text {age }}=66.8 \mathrm{mo}\right.$., $S D=$ $3.57)$. Children were tested in two private (52\% of children) and three public (48\% of children) schools in Lyon's suburban area. The two private schools included children of middle to high SES families. The public schools were located in three different neighborhoods of the same city: one in high middleclass district $(21.2 \%)$, one in a mixed neighborhood $(17 \%)$, and one in a low SES neighborhood (10\%).

\section{Materials and procedure}

The material was the same as in Experiments 1a and 1b. The experiment had two parts. The first part was identical to Experiment 1 and included the same two comprehension questions. In the second part, participants had to identify themselves with the dominant or subordinate character. Children were told that one of the characters was themselves and that the other character was a girl or a boy. Compared to Experiments $1 \mathrm{a}$ and $1 \mathrm{~b}$, the experimenter provided more details to allow the children to better project themselves in a situation that is similar to their daily interactions with other children.

The instructions began:

See? I brought this picture to show it to you, can you see what's on it? Those are children can you see them? Show them to me. Well what are these children doing: are they swimming? Are they dancing? Are they playing? Are they talking? You know what? Those children are talking together, and I can hear what they're saying to each other. Do you want me to tell you? Yes? Well...: One of the children tells the other: "You must do everything I say! Do whatever I want!" And the other child is saying: "OK! I will do what you want."

The experimenter next asked the same two comprehension questions (with their order counterbalanced: Comprehension questions (order counterbalanced): "Who is saying 'Do what I want?", "Who is saying 'OK! I will do what you want?"' In contrast to the previous studies which focused on identifying the characters' gender, the experimenter continued: "You know what? You are on this picture! In fact, on this picture there is you and a boy [girl]." The experimenter concluded by asking the two counterbalanced self-identification questions: "Now tell me: Which one in this picture is you and which one is the [other] boy [girl]." (The adjective "other' was added in the same-gender condition.) The order in which the participant ("you") and the other child were mentioned was counterbalanced across participants. Half of the children were randomly assigned to the same-gender condition, and the other half was assigned to the different-gender condition. Participants were interviewed by the same French male experimenter who was unaware of the experiment's hypotheses.

\section{Results}

Fully 146 children correctly matched postures with dominance and subordination statements $(91.25 \%, p<.001,95 \%$ CI $[85.75,95.13])$. This proportion did not significantly differ according to children's age, $\chi^{2}(1, n=160)=1.956, p=.161$, or gender, $\chi^{2}(1, n=160)=.0783, p=.779$. The following analyses only include the 146 children who correctly matched postures with dominance and subordination statements.

In the same-gender condition, children identified more with the dominant than with the subordinate character $(78.57 \%, p$ $<.001,95 \%$ CI $[67.13,87.48])$. This effect was found both for girls $(75 \%, p=.004,95 \%$ CI [57.79, 87.88]) and boys $(82.35 \% p<.001,95 \%$ CI $[65.47,93.23])$, and there was no significant difference between girls and boys, $\chi^{2}(1, n=$ $70)=.209, p=.647$. There was also no significant difference between the two age groups, $\chi^{2}(1, n=70)=.063, p=.802$. In the different-gender condition, children identified more with the dominant than with the subordinate character $(75 \%$, $p<.001,95 \%$ CI $[63.74,84.22])$. The identification with the dominant character was significant for boys $(86.68 \%$, $p<.001,95 \%$ CI $[71.91,95.58])$ but not for girls $(63.15 \%$, $p=.143 ; 95 \%$ CI $[45.99,78.18])$. Girls identified with the dominant character to a lesser extent than boys, $\chi^{2}(1, n=$ $76)=4.491, p=.034$, Cramer's $V=.24$. However, the proportion of girls who identified with the subordinate character was significantly lower than the proportion of boys who identified with the dominant character, $\chi^{2}(1, n=76)=18.066, p<.001$, Cramer's $V=.538$. Finally, there was no significant difference between the two age groups, $\chi^{2}(1, n=76)=.158, p=.691$.

\section{Discussion}

Three conclusions can be drawn from our results. First, in the same-gender condition, girls and boys showed a similar selfenhancement bias. This suggests that being dominant in an interaction was viewed as a desirable property and echoes other results indicating that preschoolers value the highpower position in various types of tasks (Bernard et al. 2016; Castelain et al. 2016; Charafeddine et al. 2016; Thomas et al. 2018). By identifying themselves with the 
high-power character, children exhibit a high opinion of themselves. This has been widely documented in the domain of personality judgments and perception of achievements (Boseovski 2010; Harter and Pike 1984; Stipek and Iver 1989) and also in the case of dominance and power (Charafeddine et al. 2019; Mandalaywala et al. 2019; Omark and Edelman 1975; Sluckin and Smith 1977; Strayer et al. 1978). Their unrealistic self-evaluations may result from a confusion between the actual self and the desired self (Harter 2006) and from the need to maintain or enhance selfesteem. Some authors argue that positive illusions about the self are beneficial to mental health because they help individuals deal with negative self-threatening experiences (Taylor and Brown 1988, 1994). In the case of status, Barkow (1975) postulated a fundamental motive for status that leads individuals, by ignoring negative status-related information and focusing on positive information, to evaluate the self as higher than others. Developmental psychologists also claimed that it may be "adaptive for a young child to overrate his position within a group and help him or her to face the initially strange and possibly frightening world of peer-group relations" (Omark et al. 1980, p. 175).

Second, the self-enhancement bias showed a different pattern in the different-gender condition: It was only observed among boys who identified more with the dominant character than did girls. It seems therefore that the male-power association interfered with children's self-representation. As shown in Experiments 1a and 1b, this association was present among girls, and in Experiment 2 it has presumably modulated their self-perception in the different-gender condition. This finding echoes the results of past studies with older participants in which dyads of children compared themselves for toughness (Edelman and Omark 1973; Omark and Edelman 1975). School-age children from girl-boy dyads disagreed less on who the tougher was than children from same-sex dyads because girls were less likely to see themselves as tougher than a boy in a girl-boy dyad. However, toughness may not be the best dimension to characterize dominance. Pickert and Wall (1981) actually found that children interpret this notion in terms of aggressive behavior (e.g., "a tough person is stronger and meaner than others and often fights with others"; Pickert and Wall 1981, p. 78) and found that "getting one's own way" was defined more as indicating power or dominance. When evaluating boys' toughness, girls might have thus taken into consideration their higher aggressiveness and focused less on relational aspects (Edwards and Whiting 1980; Fabes et al. 2003; La Freniere et al. 1984). In contrast, in our experiments, dominance was conveyed through a combination of gestures and verbal statements indicating that one individual prevailed and gave orders to another regardless of toughness.

Third, the male-power association did not fully override the self-enhancement bias in the different-gender condition, because girls did not identify more with the subordinate than with the dominant character. The comparison of Experiment 2 with Experiment 1 shows how the representation of others can differ from self-representation. In Experiment 1, girls and boys associated the dominant posture with a male character, whereas in the different-gender condition of Experiment 2, girls no longer made this association. The asymmetry between children's expectations about others and about themselves is relatively common in the literature on gender stereotypes. Adults and children produce more stereotypical answers when judging others than when judging themselves, especially when the stereotype content is negative (Cowan and Hoffman 1986; Williams and Best 1982).

The self-enhancement bias observed in the current experiment raises questions about the absence of an own-gender bias among girls in Experiments 1a and $1 \mathrm{~b}$ because own-gender favoritism and, more generally, in-group favoritism relies on the motivation for a positive self-concept (Tajel and Turner 1979). Moreover, own-gender favoritism is sometimes higher for girls than for boys (Dunham et al. 2016; Yee and Brown 1994). A possible reason for the absence of an own-gender bias in Experiments 1a and $1 \mathrm{~b}$ lies in the methodology. Children were not presented with a picture of a boy or a girl but with two nongendered and barely human silhouettes and were informed, only verbally, that one was a girl and the other was a boy. This might have been insufficient to activate gender representations relevant to self-perception and might have hindered identification with the characters. Moreover, although giving orders is a behavior that is common to both dominant boys and dominant girls (Charlesworth and Dzur 1987; Sebanc et al. 2003), physical expression of dominance through body postures might be more common among boys. In Experiment 3, we no longer use nongendered characters. A girl puppet and boy puppet are first shown to children and then hidden during the test phase. Additionally, asymmetry is no longer expressed through body postures but through verbal statements only.

\section{Experiment 3}

In Experiment 3, participants still had to determine which of a male or female character was in a powerful position, but they initially saw each of these characters through a girl or a boy puppet. A dialogue took place between the two puppets behind a concealing board during which one puppet held more power than the other. Children had to guess which puppet (the girl or the boy) occupied the powerful position and which one occupied the subordinate position. Children faced two situations. One was similar to Experiments 1-2, as the powerful puppet imposes her/his will to the other while the subordinate puppet complies. The second situation involved a puppet who had more resources than the other. We choose this situation because preschoolers and even infants consider asymmetry in resources as a cue to power (Charafeddine et al. 2015; Enright et al. 2017; Gülgöz and Gelman 2017). Moreover, using 
resource asymmetry offers a way to make cross-cultural comparisons that fit more with the gender inequality indexes used in Experiment 1b, namely, the GGGI and the GII, because these indexes rely on measures of economic power. In Experiment 3, we compare a group of French children with a group of Lebanese children. We therefore expect that Lebanese children would be more likely than French children to associate higher resources with the boy puppet. Pilot testing of this paradigm with 3-year-old children showed that children of this age group had difficulty associating the dialogues with invisible speakers as assessed by the experiment's preliminary questions. This piloting led us to conduct the experiment with only 4- and 5-year-old children.

\section{Method}

\section{Participants}

Fully 213 children $\left(M_{\text {age }}=59.5\right.$ mo., $\left.S D=6.97\right)$ from France and Lebanon participated in this experiment. All children returned written parental consent to their teachers prior to testing. The proportion of girls did not significantly differ across the two groups $(47.22 \%$ of the French sample $(n=$ $51)$ and $57.14 \%$ of the Lebanese sample $(n=60)), \chi^{2}(1, n=$ $213)=2.09 p=.147$. In France, 108 children $\left(M_{\text {age }}=60.4\right.$ mo., $S D=6.98)$ were divided into two age groups: 4-yearolds (54 children, $M_{\text {age }}=54.1 \mathrm{mo}$., $S D=3.05$ ) and 5-yearolds (54 children, $M_{\text {age }}=66.6 \mathrm{mo}$., $S D=3.18$ ). The 4-yearold group was composed of 24 girls $\left(M_{\text {age }}=54.7 \mathrm{mo}\right.$., $S D=$ 2.86 ) and 30 boys $\left(M_{\text {age }}=53.7\right.$ mo., $\left.S D=3.17\right)$, and the 5year-old group was composed of 27 girls $\left(M_{\text {age }}=67.5 \mathrm{mo}\right.$., $S D=2.85)$ and 27 boys $\left(M_{\text {age }}=65.7\right.$ mo., $\left.S D=3.29\right)$. Children came from two public schools in Lyon's periphery and one public school in its suburban area. The inhabitants of these neighborhoods are mixed between medium and low SES families.

In Lebanon, 105 children $\left(M_{\text {age }}=58.7\right.$ mo., $\left.S D=6.89\right)$ were divided into two age groups: 4-year-olds (55 children, $\left.M_{\text {age }}=52.8 \mathrm{mo} ., S D=3.41\right)$ and 5-year-olds (50 children, $M_{\text {age }}=65.1 \mathrm{mo}$., $\left.S D=2.76\right)$. The 4-year-old group was composed of 30 girls $\left(M_{a g e}=52.7\right.$ mo., $\left.S D=3.37\right)$ and 25 boys $\left(M_{\text {age }}=53\right.$ mo., $\left.S D=3.54\right)$, and the 5-year-old group was composed of 30 girls $\left(M_{a g e}=64.8\right.$ mo., $\left.S D=2.51\right)$ and 20 boys $\left(M_{\text {age }}=65.6 \mathrm{mo}\right.$., $\left.S D=3.11\right)$. Children attended a private Evangelical mission school in the city of Tyre (South Lebanon governate). Students in this school are of mixed religious backgrounds, although a majority is of Muslim Shiite background and predominantly middle-income families.

\section{Materials and procedure}

Children heard a sequence of dialogues between a girl and a boy puppet that took place behind a board. Throughout the dialogues, participants had to guess which puppet said what. The main experimenter was standing behind the board with a puppet in each hand (the position of the puppets was counterbalanced across participants). Another experimenter was seated beside the child. In Lebanon, the experimenters were both women, whereas in France, two mixed-gender pairs ran the experiments, alternating their roles. All experimenters followed the same standardized procedure. The experimenter who stood behind the board was the one who played the scenario and asked the questions. The other experimenter ensured that the child was paying attention during the dialogues and took note of the children's answers. Participants were told that the two puppets, which were designated as two children, will talk to each other and will play behind the board. They were informed that it would then not be possible to see them. To assess whether participants understood the procedure, the puppets disappeared behind the board during the instruction phase and asked the participant the first preliminary questions: "Can you see us now? But can you hear us?" Before each dialogue was played, the puppets were visible and started speaking. At some point, the puppets and the main experimenter disappeared behind the board to state the critical utterances. When the dialogue was over, they reappeared, and the experimenter asked the child who was saying what.

Six dialogues were presented in two phases: a training phase and an experimental phase. The goal of the training phase was to familiarize children with the method of asking questions about the puppets' utterances. The training phases included four dialogues presented in a fixed order, each followed by a question of the type "Who said what?" During the first two dialogues, each puppet provided explicit information about her/his gender. In the first one, as the puppets were behind the board together with the experimenter, one said, "I am girl" and the other said "I am boy" (counterbalanced order). Then, the puppets and the experimenter appeared above the board, and children had to answer the question 'Who said, 'I am a girl' and who said, 'I am a boy'?"

Following the same procedure, in the second dialogue, a puppet said, "My name is Sami/Sam" ("Sami" for Lebanese children and "Sam" for French children, which are male names in both languages), and the other puppet said, "My name is Lea" (a female name in both languages). The next two dialogues were not explicit about the puppet's gender but referred to typical preferences associated with girls or boys, which are known to children (Cunningham and Macrae 2011; LoBue and DeLoache 2011; Weisgram et al. 2014). In addition to familiarizing children with the task, these dialogues served to activate children's knowledge about gender differences in attitudes and behaviors. In particular, during the third dialogue, the puppets said that they like color pencils. Then, one of them said "I really like pink," whereas the other said "I really like blue" 
(counterbalanced order). During the fourth dialogue, in which the puppets said that they liked to play with their toys, a puppet said, "I like playing with Barbie dolls," and the other said "I like playing with motorcycles" (counterbalanced order).

In the testing phase, two dialogues involved power-related situations and were presented in a counterbalanced order. In the hide-and-seek dialogue, a conflict arises, and one of the puppets imposes its will to the other who complies. The dialogue, with the puppets still visible and talking to the child, was as follows:

Now we are going to play hide-and-seek. Do you like to play hide-and-seek? We love to play hide-and-seek. We are going to play hide-and-seek (this sentence was repeated twice, and the puppets disappeared behind the board):

[Puppets behind the board]

Puppet 1: I count.

Puppet 2: Oh no, I count, I like to count.

Puppet 1: So what? I decide. I like to count too, and I decide. I choose who counts and who doesn't. I choose everything.

Puppet 2: Ah ok, so I choose nothing.

Puppet 1: Yes, that's it. And then when this game is over, I will choose what other games we will play. I choose everything.

Puppet 2: Oh, OK, I choose nothing.

The experimenter then asks the child (in counterbalanced order): "Who did say 'I choose everything, I decide everything"" and "Who did say 'I choose nothing; I decide nothing?" In the resource asymmetry dialogue, puppets announce their amounts of money in a context where they want to buy ice cream. The dialogue (with the puppets still visible and talking to the child) was as follows:

We are going to buy ice cream... Hum, here comes the ice-cream seller, we have to catch up with him. The icecream seller! The ice-cream seller! We want to buy ice cream.

[Puppets disappear behind the board]:

Puppet 1: I have 10 pennies in my pocket, I have a lot of money.
Puppet 2: I have 3 pennies in my pocket, I don't have a lot of money.

Puppet 1: I have a lot of money.

Puppet 2: I don't have a lot of money.

In French, we used the word "sous" which is a casual and generic word for money (uncountable usage) and monetary units (countable usage). In Lebanon, we used 1000 pound units (3000 pounds versus 10,000 pounds), which is the unit that is most frequently used in the country. After the dialogue, the experimenter asked the child (in counterbalanced order): "Who said, 'I have a lot of money" and "Who said, 'I don't have a lot of money?"”

\section{Results}

In the training phase, all children correctly answered the questions about the puppet's genders and names and thus understood the task consisting of assigning the puppets' gender to the puppets' statements. Moreover, $92 \%(n=196)$ of the children indicated that the girl puppet liked pink and the boy puppet liked blue. Finally, 98\% $(n=209)$ of children indicated that the girl puppet liked to play with Barbie dolls whereas the boy puppet liked to play with the motorbike. These results indicate that children displayed standard gender stereotypes regarding toys and colors.

We now turn to the testing phase. In the hide-and-seek situation, $58.21 \%(n=126)$ of children indicated that it was the boy puppet who said "I choose everything" and the girl puppet who said "I choose nothing" $(p=.0196,95 \%$ CI $[51.28,64.91])$. There was no significant difference between Lebanese and French children $(58.09 \%$ vs. $58.33 \%), \chi^{2}(1$, $n=213)=.001, p=.971$, or between 4- and 5-year-olds $(57.79 \%$ vs. $58.65 \%), \chi^{2}[1, n=213]=.002, p=.899$, but there was a significant effect of participants' gender because boys were more likely to attribute the dominant position to the boy puppet than were girls ( $73.52 \%$ vs. $44.14 \%), \chi^{2}(1, n=$ $213)=18.87, p<.001$, Cramer's $V=.29$. Among boys, the tendency to attribute the dominant position to the boy puppet significantly differed from chance $(p<.001)$ but this was not the case among girls $(p=.254)$. More specifically, in Lebanon, $41.66 \%$ of girls associated the dominant position with the boy puppet ( $p=.245,95 \%$ CI $[44.88,70.93])$, and $80 \%$ of the boys did so $(p<.001,95 \%$ CI $[65,90])$. In France, $47.06 \%$ of girls associated the dominant position with the boy puppet $(p=.779,95 \%$ CI $[38.46,67.07])$ and $68.42 \%$ of the boys did so $(p=.007,95 \%$ CI $[55.76,80.09])$. In France, where experimenters could be male or female, the gender of the experimenter had no significant effect: $55.81 \%$ of the children who heard a male voice made the male-power association 
versus $60 \%$ of the children who heard a female voice, $\chi^{2}(1$, $n=108)=.187, p=.666$.

In the resource asymmetry situation, the results showed a similar pattern. Overall, $60.56 \%(n=129)$ of the children indicated that it was the boy puppet who said, "I have a lot of money" and the girl puppet who said, "I don't have a lot of money" ( $p=.002,95 \%$ CI $[53.65,67.17])$. There was no significant difference between Lebanese and French children $(57.14 \%$ vs. $63.89 \%), \chi^{2}(1, n=213)=1.014, p=.314$, or between 4 - and 5-year-olds (57.8\% vs. $63.46 \%), \chi^{2}(1, n=$ $213)=.715, p=.398$, but there was a significant effect of participants' gender because boys were more likely to attribute the dominant position to the boy puppet than were girls $(72.55 \%$ vs. $49.55 \%), \chi^{2}(1, n=213)=18.869, p<.001$, Cramer's $V=.23$. The tendency to attribute the dominant position to the boy puppet significantly differed from chance among boys ( $p<.001,95 \%$ CI $[62.82,80.92])$ but not among girls $(p=.925,95 \%$ CI $[39.92,59.20]$. More specifically, in Lebanon, $48.33 \%$ of the girls $(p=.897,95 \%$ CI $[38.39,64.77])$ and $68.89 \%$ of the boys $(p=.016,95 \%$ CI $[53.35,81.81])$ judged that the boy puppet had more money. In France, $50.98 \%$ of the girls $(p=.912,95 \% \mathrm{CI}$ $[36.59,65.24])$ and $75.44 \%$ of the boys $(p<.001,95 \%$ CI $[62.24,85.87])$ judged that the boy puppet was richer. Again, the gender of the experimenter had no effect: $58.14 \%$ of the children who heard a male voice made the male-power association versus $67.69 \%$ of the children who heard a female voice, $\left.\chi^{2}(1, n=108)=1.023, p=.312\right)$.

\section{Discussion}

The results show different response patterns for boys and girls in both scenarios. While a majority of boys associated the boy character with the dominant position, girls' responses were at chance levels. In light of previous findings indicating that boys and girls have the same ability to detect hierarchical relations (Brey and Shutts 2015; Charafeddine et al. 2015; Gülgöz and Gelman 2017), it is implausible that girls answered randomly. The most likely interpretation is that the male-power association was dampened by an own-gender bias that led some girls to attribute the dominant position to the girl puppet.

Overall the results of Experiment 3 indicate that preschool children use gender as a cue to power, not only when one agent imposes their will on another but also when one individual controls more resources. This result contrasts with research reporting that children do not use gender to predict a wealth asymmetry (Mandalaywala et al. 2019; Olson et al. 2012). In those studies, participants had to assess who between a female or a male target lives in a high-value house and who lives in a low-value house. As the authors of these studies themselves note, children are unlikely to see differences between males and females with respect to housing conditions, whereas this dimension is more relevant to predict status differences between racial groups. Living in a house or taking advantage of other lifestyle-related goods like cars, largely concerns family units composed of both male and female members, which may explain why children do not relate this type of wealth to a specific gender.

In the current experiment, the asymmetry operates at a different level. The resources do not concern living conditions but involve the possibility of achieving a specific goal, namely the purchase of ice-cream, which is explicitly presented as relevant to the puppets and which is probably relevant to the participants as well. The relevance of the goods may influence how children relate asymmetry of resources to gender. For example, in Mandalaywala et al. (2019), children (from 3.5 to 6.5 years-old) did not associate gender with wealth in the house-matching task described previously, but they did so when the resources were specifically relevant to children (i.e. having lots of toys and new clothes; always getting to pick the tasks that everyone else plays at recess and the snacks that everyone else eats at snack time). Participants associated a male child target with a higher status than a female child target, and, as in the current experiment, this association was stronger for male than female participants. Moreover, in our task, the asymmetry of resources might be more directly related to the notion of power because of the interactive context in which it appears. Specifically, although the two puppets have the same goal (to buy ice cream), the richer puppet has more power to gain access to the goods and therefore to control the situation. The association between resources and gender in the current experiment may be influenced by the power dynamics that stem directly from it. Finally, as in Experiment $1 b$, we found no difference between children from the two countries, even though the resource asymmetry scenario fitted more with indexes of gender inequality.

\section{General Discussion}

Through a series of four experiments, we investigated children's representations of the link between gender and power that led to three main findings. First, children were overall more likely to associate power with a male than with a female character. This was found in several age groups, in several countries (France, Lebanon, and Norway), and equally among girls and boys in Experiments $1 \mathrm{a}$ and $1 \mathrm{~b}$. Moreover, Experiment 2 showed that the male-power association was not limited to third-party relations but also influenced how children, particularly girls, viewed themselves. The second important result is the difference between girls' and boys' response patterns in some situations. In the different-gender condition of Experiment 2, boys identified themselves more with the dominant character than did girls. Moreover, in Experiment 3, a large majority of male participants considered 
that the puppet who imposed its choice and who controlled more resources was the boy puppet, whereas this was not the case for female participants. The third main finding is the lack of difference between participants from societies that differ in their level of gender inequality (Experiments $1 \mathrm{~b}$ and 3 ).

\section{Early Representation of Male Power}

The male-power association observed for children as young as 4 years-old contrasts with earlier studies in which the youngest children (6-8-year-olds) did not perceive gender inequality or perceived it to a lower degree than older children (Liben et al. 2001; Neff et al. 2007). However, those studies relied on more complex entities, such as occupational interests or job remuneration (Liben et al. 2001; Weisgram et al. 2010) or used a methodology that asked children to consider power and gender in abstract ways (men and women as general entities; Neff et al. 2007). In the current experiments, preschoolers had to consider power and gender through concrete dyadic relationships between actual characters who displayed explicit verbal and nonverbal behavior. This methodology, which had proved to be successful at demonstrating preschoolers' and infants' ability to represent dominance and power, probably facilitated the association between gender and power at preschool age.

However, Experiments $1 \mathrm{a}$ and $1 \mathrm{~b}$ suggest that the malepower association does not emerge before age four. This might be due to less stable representations of power based on postures for the youngest children (Charafeddine et al. 2019; Terrizzi et al. 2018). More generally, 3-year-old children may also be less likely to use gender as a relevant cue to power. They have poorer experience of mixed-gender interactions than older children, and the cognitive mechanisms that allow them to make sense of asymmetrical relationships are less sophisticated (Gülgöz and Gelman 2017, Over and Carpenter 2015). In addition, the task itself might have been too difficult for the youngest children because assigning a specific gender to a non-gendered character is a relatively abstract process. Finally, another explanation relies on the predominance of female authority figures in young children's educational and domestic environments (i.e., parents and teachers). Three-year-old children are more dependent on authority figures than older children when they have to make decisions and obtain relevant information. Given that authority figures are more often women, they might be less likely to assign higher power to males than older children are.

\section{The Influence of Participants' Gender}

Participants' gender produced mixed results regarding the male-power association. Whereas Experiments $1 \mathrm{a}$ and $1 \mathrm{~b}$ showed that girls and boys associated power with a male character to a similar extent, this was not the case in Experiments 2 and 3. In those latter experiments, the association was stronger among boys than among girls, who answered at chance levels. In particular, when implicating the self in the relationship, as in Experiment 2, girls did not ascribe the powerful position to a boy character more than to themselves. This similarity most likely stems from a self-enhancement bias, which was observed in the same gender condition and in other studies (Charafeddine et al. 2019; Edelman and Omark 1973; Mandalaywala et al. 2019; Omark and Edelman 1975; Sluckin and Smith 1977; Strayer et al. 1978). This result therefore nuances the view that girls attribute negative value to female power.

In Experiment 3, although a large majority of boys considered that the puppet who imposed its choice and who had more resources was the boy puppet, this was not the case for girls. This difference can be accounted for by own-gender favoritism leading some girls to attribute the socially advantageous position to an individual of their own gender. The gender effect obtained in Experiment 3 echoes that observed in Experiment 2 because own-gender favoritism partially relies on positive self-views (Tajfel and Turner 1979). In Experiments $1 \mathrm{a}$ and $1 \mathrm{~b}$, the absence of own-gender bias might have resulted from the limited gender-related information that we provided, whereas in Experiment 3 the gender of the characters was clearly identifiable and gender-related information was made salient in preliminary questions. The greater salience of gender may have led a subgroup of the female participants to identify with the girl puppet, thus giving her the advantageous position. However, Experiments $1 \mathrm{a}$ and $1 \mathrm{~b}$ also involved physical postures that were absent in Experiment 3. Therefore, it cannot be ruled out that postures hindered the own-gender bias in girls and strengthened the male-power association in Experiments $1 \mathrm{a}$ and $1 \mathrm{~b}$.

\section{Absence of Cultural Differences}

Overall, the current experiments included participants from three different countries but showed no influence of culture. Although this result does not confirm our prediction, it shows that the power-masculinity association and the difference between boys and girls were robust. Our results could reflect that even in countries where gender equality is fostered at a formal political level, which is the case in Norway and in France to a lesser extent, some inter-gender relations still give advantageous positions to men (Baxter and Kane 1995). Moreover, in countries in which social attitudes emphasize gender equality, some features of the children's environment, such as toy collections, display marked gender roles that are similar to those in less egalitarian countries (Nelson 2005).

Research has shown that preschoolers from various cultural backgrounds can have similar gender stereotypes, as reflected in their toy preferences and play (Turner et al. 1993), as well as their behavioral and psychological traits (Best et al. 1977; 
Williams and Best 1982). For instance, in their wide-range cross-cultural study, which included 25 countries, Williams and Best (1982) reported that 5-year-olds associated traits such as weak and softhearted with female individuals and aggressiveness and strength with males. Moreover, the developmental pattern of gender stereotypes was relatively similar across countries, although the learning rates could differ (Williams and Best 1982). Typically, in most cultures, stereotypes emerge before the age of five; they then show a relatively sharp increase during school years and are fully acquired during adolescence (Williams and Best 1982).

In the current study, children might have been too young to show an acute sensitivity to the level of gender inequality in their environment, which could have resulted in intercultural differences. Given that the power asymmetry between genders is universal and that physical traits associated with dominance differ between males and females in a similar way across cultures, children might develop initial and rough representations that associate power with male figures to the same extent. It might be only at later ages that gender representations integrate societal inputs that either foster or discourage power asymmetry between genders. Indeed, by the end of their elementary schooling, children's gender concepts become more flexible and less normative (Levy et al. 1995; Taylor et al. 2009).

\section{Limitations and Further Research Directions}

Although our work is one of the first known to explore how preschool children represent the relationship between gender and power in interactive contexts and in different cultures, it contains several limitations that call for complementary studies. A first limitation concerns the participants' age range. It was relatively narrow compared to earlier developmental work on the representation of gender inequalities, which included school-age children, adolescents, and adults (Liben et al. 2001; Neff et al. 2007; Weisgram et al. 2010). Those studies found that for more societal dimensions of hierarchy (e.g., job occupations), the association between high-status and maleness tends to reinforce with age. In our study we did not find any difference between the 4 year-olds and 67 year-olds, but investigating older children would be helpful at better characterizing the developmental pathway of power representations related to gender. On the on hand, because children expect more equality in relationships as they grow older (Shaw and Olson 2012), the male-power association might decline with age. On the other hand, the accumulation of observations of male-female asymmetric interactions can result in strengthening their belief in a male power. The age range issue also concerns younger children. Although we found no evidence of a male-power association among 3year-old children, further research is needed to explore whether more appropriate stimuli may elicit such an association.
Another limitation concerns the implementation of power relationships. In Experiments 1 and 2, the power asymmetry was conveyed through a combination of verbal statements and physical postures. However, the physical expression of dominance through facial traits, muscular strength, postures, size, or voice also correlates with physical differences between males and females. For instance, expanded and erect body postures, which typically convey dominance, occupy more physical space than constricted postures, but this is also the case of male physical behavior and male body size as compared to female ones. In Experiments 1 and 2, although the two characters are of the same size, the dominant character has its arm and its finger directed toward the subordinate and has its head up. In contrast, the subordinate occupies less space because its arm is not visible, and its head is down. This may give the impression that the subordinate is smaller. Some participants could thus have based their gender assignment only on perceptual cues without considering the power difference in the interaction. However, some results are not consistent with this possibility. In Experiments $1 \mathrm{a}$ and $1 \mathrm{~b}$ children who failed to answer the comprehension questions were at chance level when responding to the gender attribution questions. This finding suggests that, for these children, the perceptual features were not sufficient to infer maleness from the erect-body character.

A related point that needs to be explored is the possibility that some expressions of power are more associated to one gender than to another. Although in our task the erect-body posture differs from typical aggressive behavior such as hitting, pushing or threatening, the dominant character may look aggressive because of its antisocial behavior: the dominant imposes its will on the subordinate who has no choice but to obey. Adopting an antisocial behavior is often a consequence of exercising power (Guinote et al. 2015; Lammers and Stapel 2011). Preschoolers are sensitive to this dimension because they are more likely to infer power from antisocial and malevolent behavior (e.g., mean, unhelpful) than from pro-social and benevolent behavior (Gülgöz and Gelman 2017; Terrizzi et al. 2019). This aspect of power may guide children in their gender assignation. In particular, if they tend to view boys as more physically aggressive than girls (Giles and Heyman 2005), they might infer that the powerful individual is a boy. Hence, future research should more systematically explore how children associate various expressions of power with gender. In particular, if preschoolers use aggressiveness to assign power to boys, they might be less likely to do so when power manifests itself in a more benevolent form. One difficulty, however, is that preschoolers may have more trouble inferring power from benevolent behavior (Gülgöz and Gelman 2017).

Another limitation concerns cross-cultural comparisons. The societies we have chosen may not be the best at bringing out cross-cultural differences in children of the ages we studied. The criteria of gender inequality that we took into account are on a societal level and do not necessarily capture what 
happens on a more local level or in specific culturally embedded interactions. Microscale societies that emphasize the importance of women in valued social areas would be worthy of study, such as matrilineal societies in which property, titles, land or family names can be passed down through the lineage of the mother. Interestingly, in women from matrilineal societies, the attitude toward aspects of social hierarchies, such as competition or economic resources, resembles that of men from more patriarchal societies. For instance, it has been observed that among the Khasi, women are more likely to take part in competitive activities than men (Gneezy et al. 2009). Similarly, among the Mosuo, in which women are in charge of economic power, a study found that women shared their monetary resources in the dictator game half the time compared to men (Gong et al. 2015), whereas the opposite pattern has been observed in western societies (Eckel and Grossman 1998; Selten and Ockenfels 1998). Moreover, within western societies, educational practices, at school or in the family circle, which promote gender equality and/or gender neutrality, can also have an impact on children's representations of gender. Indeed, gender-neutral pedagogy tends to reduce gender stereotyping among preschoolers (Shutts et al. 2017) compared to typical pedagogy, whereas school environments that emphasize gender distinctions increase gender stereotypes and negative attitudes toward different-gender peers (Hilliard and Liben 2010).

Finally, future research could use finer ways to code participants' gender. In our study, as in most studies on children's social cognition, binary gender categories are used that directly correspond to participants' sex. Finer grained results could be obtained by using children's felt gender identity as an intersubject variable (Bem 1981; Martin et al. 2017).

\section{Practice Implications}

A first implication of the current research is that kindergarten schools and educational institutions not only should be responsive to gendered divisions based on groups, which typically associate distinct toys, activities, and linguistic labelling to distinct genders, but also should consider the relational dynamics inherent to gender. Not only do children have different expectations about the psychological traits of males and females, but they also have expectations about the outcomes of interactions in cross-gender interactions, as demonstrated by the current study. From the perspective of intervention, gender inequality should thus also encompass girl-boy power dynamics and their representation of a gendered power.

A second implication is that the current work can inform educational practices about the age at which gender-based power relations begin to play an important role in children's social expectations and self-construal. Our studies show that children understand gender inequality in its relational manifestation before they understand gender differences in social status. By using power relations as a manifestation of gender inequality, educational programs for gender equality can target children since their first preschool years. Moreover, intervention programs can use children's abilities to infer power from a wide range of cues to present inter-gender interactions that go against stereotypical male dominance. Finally, thinking from a first-person perspective seems to incite girls to moderate their expectations of male power. In this regard, implicating the self, by inviting children to act in fictitious social power situations or through explicit identification with third party characters, may prove fruitful.

\section{Conclusions}

Gender hierarchy relies on power and produces important power asymmetries in the social world. The current study used asymmetric power interactions to examine children's representations of cross-gender relations and to show early sensitivity to a hierarchy between males and females. The social inferences that children draw from gender categories is a central issue for developmental psychology because of its obvious implication in social prejudices and in children's conceptions of their social selves. As Erving Goffman (1977, p. 301) put it: "In modern industrial society, as apparently in all others, sex is at the base of a fundamental code in accordance with which social interactions and social structures are built up, a code which also establishes the conceptions individuals have concerning their fundamental human nature." The current study and the corresponding line of research should contribute to a more fine-grained understanding of the way gender power relations are used and reproduced in development.

Acknowledgements Rawan Charafeddine Laboratoire Langage Cerveau Cognition, Institut des Sciences Cognitives Marc Jeannerod; Imac Maria Zambrana, Faculty of Educational Science, Department of Special Needs Education, University of Oslo; Benoît Triniol, Laboratoire Langage Cerveau Cognition, Institut des Sciences Cognitives Marc Jeannerod; Hugo Mercier, Laboratoire Langage Cerveau Cognition, Institut des Sciences Cognitives Marc Jeannerod; Fabrice Clément, Centre de Sciences Cognitives, Université de Neuchâtel; Laurence Kaufmann, Institut des Sciences Sociales, Faculté des Sciences Sociales et Politiques, Lausanne University; Anne Reboul, Laboratoire Langage Cerveau Cognition, Institut des Sciences Cognitives Marc Jeannerod; Francisco Pons, Faculty of Social Sciences, Department of Psychology, University of Oslo; Jean-Baptiste Van der Henst, Laboratoire Langage Cerveau Cognition, Institut des Sciences Cognitives Marc Jeannerod

We wish to thank Emily Hewitt, Bérangère Testud, Mayssan Charafeddine, Léonore Ferrer Catala and Antoine Danielou for help with data collection. We also thank the participating children and their parents, the schools and Inspection Académique de Lyon, in particular Sylvie Coustier, Stéphane Garapon, Vincent Guili and Michèle Prieur, for making this research possible. We thank Gloria Origgi for her valuable input; Justine Epinat, Thomas Castelain, Audrey Breton, Thomas CharavetGomel and Ira Noveck for their support and two anonymous reviewers for their helpful comments. This research was supported by a grant from Fondation de France and by CNRS (Défi Genre) awarded to the last author. 


\section{References}

Agresti, A. (2002). Categorical data analysis (2nd ed.). New York: Wiley. https://doi.org/10.1002/0471249688.

Albert, A. A., \& Porter, J. R. (1986). Children's gender role stereotypes: A comparison of the United States and South Africa. Journal of Cross-Cultural Psychology, 17(1), 45-65. https://doi.org/10.1177/ 0022002186017001004.

Anderson, K. J., \& Leaper, C. (1998). Meta-analyses of gender effects on conversational interruption: Who, what, when, where, and how. Sex Roles, 39(3-4), 225-252. https://doi.org/10.1023/A: 1018802521676.

Barkow, J. H. (1975). Prestige and culture: A biosocial interpretation. Current Anthropology, 16(4), 553-563. https://www.jstor.org/ stable/2741630.

Baxter, J., \& Kane, E. W. (1995). Dependence and independence: A cross-national analysis of gender inequality and gender attitudes. Gender \& Society, 9(2), 193-215. https://doi.org/10.1177/ 089124395009002004

Bem, S. L. (1981). Gender schema theory: A cognitive account of sex typing. Psychological Review, 88(4), 354-364. https://doi.org/10. 1037/0033-295x.88.4.354.

Bernard, S., Castelain, T., Mercier, H., Kaufmann, L., Van der Henst, J.B., \& Clément, F. (2016). The boss is always right: Preschoolers endorse the testimony of a dominant over that of a subordinate. Journal of Experimental Child Psychology, 152, 307-317. https:// doi.org/10.1016/j.jecp.2016.08.007.

Best, D. L., Williams, J. E., Cloud, J. M., Davis, S. W., Robertson, L. S., Edwards, J. R., ... Fowles, J. (1977). Development of sex-trait stereotypes among young children in the United States, England, and Ireland. Child Development, 48, 1375-1384. https://doi.org/10. 1111/j.1467-8624.1977.tb03943.x.

Bianchi, S. M., Milkie, M. A., Sayer, L. C., \& Robinson, J. P. (2000). Is anyone doing the housework? Trends in the gender division of household labor. Social Forces, 79(1), 191-228. https://doi.org/10. 1093/sf/79.1.191.

Bird, R. (1999). Cooperation and conflict: The behavioral ecology of the sexual division of labor. Evolutionary Anthropology, 8(2), 65-75. https://doi.org/10.1002/(sici)1520-6505(1999)8:2\%3C65::aidevan5\%3E3.3.co;2-v.

Birnbaum, D. W., \& Chemelski, B. E. (1984). Preschoolers' inferences about gender and emotion: The mediation of emotionality stereotypes. Sex Roles, 10(7-8), 505-511.

Birnbaum, D. W., Nosanchuk, T. A., \& Croll, W. L. (1980). Children's stereotypes about sex differences in emotionality. Sex Roles, 6(3), 435-443. https://doi.org/10.1007/BF00287363.

Boseovski, J. J. (2010). Evidence for "rose-colored glasses": An examination of the positivity bias in young children's personality judgments. Child Development Perspectives, 4(3), 212-218. https://doi. org/10.1111/j.1750-8606.2010.00149.x.

Brey, E., \& Shutts, K. (2015). Children use nonverbal cues to make inferences about social power. Child Development, 86(1), 276286. https://doi.org/10.1111/cdev.12334.

Brightman, R. (1996). The sexual division of foraging labor: Biology, taboo, and gender politics. Comparative Studies in Society and History, 38(4), 687-729. https://doi.org/10.1017/ s0010417500020508.

Bussey, K., \& Bandura, A. (1999). Social cognitive theory of gender development and differentiation. Psychological Review, 106(4), 676-713. https://doi.org/10.1037/0033-295x.106.4.676.

Carli, L. L. (1999). Gender, interpersonal power, and social influence. Journal of Social Issues, 55(1), 81-99. https://doi.org/10.1111/ 0022-4537.00106.

Cashdan, E. (1998). Smiles, speech, and body posture: How women and men display sociometric status and power. Journal of Nonverbal
Behavior, 22(4), 209-228. https://doi.org/10.1023/A: 1022967721884.

Castelain, T., Bernard, S., Van der Henst, J. B., \& Mercier, H. (2016). The influence of power and reason on young Maya children's endorsement of testimony. Developmental Science, 19(6), 957-966. https:// doi.org/10.1111/desc.12336.

Charafeddine, R., Mercier, H., Kaufman, L., Clement, F., Berchtold, A., Reboul, A., ... Van Der Henst, J.-B. (2015). How preschoolers use cues of dominance to make sense of their social environment. Journal of Cognition and Development, 16(4), 587-604. https:// doi.org/10.1080/15248372.2014.926269.

Charafeddine, R., Mercier, H., Clément, F., Kaufmann, L., Reboul, A., \& Van Der Henst, J.-B. (2016). Children's allocation of resources in social dominance situations. Developmental Psychology, 52(11), 1843-1857. https://doi.org/10.1037/dev0000164.

Charafeddine, R., Yamada, Y., Matsui, T., Sudo, M., Germain, P., Bernard, S., ... Van Der Henst, J.-B. (2019). Cross-cultural differences in the valuing of dominance by young children. Journal of Cognition and Culture, 19(3-4), 256-272. https://doi.org/10.1163/ 15685373-12340058.

Charlesworth, W. R., \& Dzur, C. (1987). Gender comparisons of preschoolers' behavior and resource utilization in group problem solving. Child Development, 58(1), 191-200. https://doi.org/10.2307/ 1130301

Clément, F., Harris, P., Bernard, S., Antonietti, J.-P., \& Kaufmann, L. (2014). Rousseau's child. Swiss Journal of Psychology, 73(2), 105-110. https://doi.org/10.1024/1421-0185/a000129.

Cogsdill, E. J., Todorov, A. T., Spelke, E. S., \& Banaji, M. R. (2014). Inferring character from faces. Psychological Science, 25(5), 11321139. https://doi.org/10.1177/0956797614523297.

Cowan, G., \& Hoffman, C. D. (1986). Gender stereotyping in young children: Evidence to support a concept-learning approach. Sex Roles, 14(3-4), 211-224. https://doi.org/10.1007/bf00288250.

Crick, N. R., \& Grotpeter, J. K. (1995). Relational aggression, gender, and social-psychological adjustment. Child Development, 66(3), 710 722. https://doi.org/10.2307/1131945.

Crick, N. R., Casas, J. F., \& Mosher, M. (1997). Relational and overt aggression in preschool. Developmental Psychology, 33(4), 579588. https://doi.org/10.1037/0012-1649.33.4.579.

Cunningham, S. J., \& Macrae, C. N. (2011). The colour of gender stereotyping. British Journal of Psychology, 102(3), 598-614. https://doi.org/10.1111/j.2044-8295.2011.02023.x.

Darmangeat, C. (2009). Le communisme primitif n'est plus ce qu'il était : Aux origines de l'oppression des femmes [primitive communism is no longer what it was: The origins of women's oppression]. Toulouse: Smolny.

Dovidio, J. F., Ellyson, S. L., Keating, C. F., Heltman, K., \& Brown, C. E. (1988). The relationship of social power to visual displays of dominance between men and women. Journal of Personality and Social Psychology, 54(2), 233-242. https://doi.org/10.1037/0022-3514.54. 2.233 .

Dunham, Y., Baron, A. S., \& Banaji, M. R. (2016). The development of implicit gender attitudes. Developmental Science, 19(5), 781-789. https://doi.org/10.1111/desc.12321.

Eagly, A. H., Makhijani, M. G., \& Klonsky, B. G. (1992). Gender and the evaluation of leaders: A meta-analysis. Psychological Bulletin, 111(1), 3-22. https://doi.org/10.1037/h0090375.

Eckel, C. C., \& Grossman, P. J. (1998). Are women less selfish than men?: Evidence from dictator experiments. The Economic Journal, 108(448), 726-735. https://doi.org/10.1111/1468-0297. 00311.

Edelman, M. S., \& Omark, D. R. (1973). Dominance hierarchies in young children. Social Science Information, 12(1), 103-110. https://doi. org/10.1177/053901847301200105.

Edwards, C. P., \& Whiting, B. B. (1980). Differential socialization of girls and boys in light of cross-cultural research. New Directions for Child 
and Adolescent Development, 1980(8), 45-57. https://doi.org/10. 1002/cd.23219800807.

Enright, E. A., Gweon, H., \& Sommerville, J. A. (2017). 'To the victor go the spoils': Infants expect resources to align with dominance structures. Cognition, 164, 8-21. https://doi.org/10.1016/j.cognition. 2017.03.008.

Esposito, A. (1979). Sex differences in children's conversation. Language and Speech, 22(3), 213-220. https://doi.org/10.1177/ 002383097902200302

Fabes, R. A., Martin, C. L., \& Hanish, L. D. (2003). Young children's play qualities in same-, other-, and mixed-sex peer groups. Child Development, 74(3), 921-932. https://doi.org/10.1111/1467-8624. 00576.

Fagot, B. I., Leinbach, M. D., \& O'boyle, C. (1992). Gender labeling, gender stereotyping, and parenting behaviors. Developmental Psychology, 28(2), 225-230. https://doi.org/10.1037/0012-1649. 28.2.225.

Fagot, B. I., Rodgers, C. S., \& Leinbach, M. D. (2012). Theories of gender socialization. In T. Eckes \& H. Trautner (Eds.), The developmental social psychology of gender (pp. 79-104). Mahwah: Lawrence Erlbaum Associates Publishers.https://www. taylorfrancis.com/books/e/9781410605245/chapters/10.4324/ 9781410605245-10.

Fehr, E., Bernhard, H., \& Rockenbach, B. (2008). Egalitarianism in young children. Nature, 454(7208), 1079-1083. https://doi.org/10. 1038/nature07155.

Fishbein, H. D., \& Imai, S. (1993). Preschoolers select playmates on the basis of gender and race. Journal of Applied Developmental Psychology, 14(3), 303-316. https://doi.org/10.1016/01933973(93)90012-k.

Fiske, S. T., Cuddy, A. J., Glick, P., \& Xu, J. (2002). A model of (often mixed) stereotype content: Competence and warmth respectively follow from perceived status and competition. Journal of Personality and Social Psychology, 82(6), 878-902. https://doi. org/10.1037/0022-3514.82.6.878.

Fiske, S. T., Cuddy, A. J., \& Glick, P. (2007). Universal dimensions of social cognition: Warmth and competence. Trends in Cognitive Sciences, 11(2), 77-83. https://doi.org/10.1016/j.tics.2006.11.005.

Gazes, R. P., Hampton, R. R., \& Lourenco, S. F. (2017). Transitive inference of social dominance by human infants. Developmental Science, 20(2), e12367. https://doi.org/10.1111/desc.12367.

Giles, J. W., \& Heyman, G. D. (2005). Young children's beliefs about the relationship between gender and aggressive behavior. Child Development, 76(1), 107-121. https://doi.org/10.1111/j.1467-8624. 2005.00833.x.

Gneezy, U., Leonard, K. L., \& List, J. A. (2009). Gender differences in competition: Evidence from a matrilineal and a patriarchal society. Econometrica, 77(5), 1637-1664. https://doi.org/10.3386/w13727.

Goffman, E. (1977). The arrangement between the sexes. Theory and Society, 4(3), 301-331. https://doi.org/10.1007/bf00206983.

Gong, B., Yan, H., \& Yang, C.-L. (2015). Gender differences in the dictator experiment: Evidence from the matrilineal Mosuo and the patriarchal Yi. Experimental Economics, 18(2), 302-313. https:// doi.org/10.2139/ssrn.1655689.

Guinote, A., Cotzia, I., Sandhu, S., \& Siwa, P. (2015). Social status modulates prosocial behavior and egalitarianism in preschool children and adults. Proceedings of the National Academy of Sciences, 112(3), 731-736. https://doi.org/10.1073/pnas.1414550112.

Gülgöz, S., \& Gelman, S. A. (2017). Who's the boss? Concepts of social power across development. Child Development, 88(3), 946-963. https://doi.org/10.1111/cdev.12643.

Halim, M. L., Ruble, D. N., \& Tamis-LeMonda, C. S. (2013). Four-yearolds' beliefs about how others regard males and females. British Journal of Developmental Psychology, 31(1), 128-135. https://doi. org/10.1111/j.2044-835X.2012.02084.x.
Hall, J. A., Coats, E. J., \& LeBeau, L. S. (2005). Nonverbal behavior and the vertical dimension of social relations: A meta-analysis. Psychological Bulletin, 131(6), 898-924. https://doi.org/10.1037/ 0033-2909.131.6.898.

Harter, S. (2006). The self. In W. Damon, R. M. Lerner, \& N. Eisenberg (Eds.), Handbook of child psychology: Social, emotional, and personality development (Vol. 3, 6th ed., pp. 505-570). New Jersey: Wiley. https://doi.org/10.1002/9780470147658.chpsy0309

Harter, S., \& Pike, R. (1984). The pictorial scale of perceived competence and social acceptance for young children. Child Development, 55(6), 1969-1982. https://doi.org/10.1037/t04621-000.

Hawley, P. H. (1999). The ontogenesis of social dominance: A strategybased evolutionary perspective. Developmental Review, 19(1), 97132. https://doi.org/10.1006/drev.1998.0470.

Hayden-Thomson, L., Rubin, K. H., \& Hymel, S. (1987). Sex preferences in sociometric choices. Developmental Psychology, 23(4), 558-562. https://doi.org/10.1037/0012-1649.23.4.558.

Henley, N. (1977). Body politics: Power, sex, and nonverbal communication. New Jersey: Prentice Hall. https://doi.org/10. 2307/2065224.

Henley, N. M., \& Harmon, S. (1985). The nonverbal semantics of power and gender: A perceptual study. In S. L. Ellyson \& J. F. Dovidio (Eds.), Power, dominance, and nonverbal behavior (pp. 151-164). New York: Springer. https://doi.org/10.1007/978-1-4612-5106-4 8.

Hilliard, L. J., \& Liben, L. S. (2010). Differing levels of gender salience in preschool classrooms: Effects on children's gender attitudes and intergroup bias. Child Development, 81(6), 1787-1798. https://doi. org/10.1111/j.1467-8624.2010.01510.x.

Horne, R. M., Johnson, M. D., Galambos, N. L., \& Krahn, H. J. (2018). Time, money, or gender? Predictors of the division of household labour across life stages. Sex Roles, 78(11), 731-743. https://doi. org/10.1007/s11199-017-0832-1.

Human Rights Watch. (2015). Unequal and unprotected: Women's rights under Lebanon's religious personal status laws. https://doi.org/10. 1163/2210-7975 hrd-2156-2015061.

Keating, C. F., \& Bai, D. L. (1986). Children's attributions of social dominance from facial cues. Child Development, 57(5), 1269 1276. https://doi.org/10.1111/j.1467-8624.1986.tb00454.x.

Kinzler, K. D., Shutts, K., \& Correll, J. (2010). Priorities in social categories. European Journal of Social Psychology, 40(4), 581-592. https://doi.org/10.1002/ejsp.739.

Kuhn, D., Nash, S. C., \& Brucken, L. (1978). Sex role concepts of twoand three-year-olds. Child Development, 49(2), 445-451. https:// doi.org/10.2307/1128709.

La Freniere, P., Strayer, F. F., \& Gauthier, R. (1984). The emergence of same-sex affiliative preferences among preschool peers: A developmental/ethological perspective. Child Development, 55(5), 1958-1965. https://doi.org/10.1111/j.1467-8624.1984.tb00437.x.

Lakoff, R. (1973). Language and woman's place. Language in Society, 2(1), 45-79. https://doi.org/10.1017/s0047404500000051.

Lammers, J., \& Stapel, D. A. (2011). Power increases dehumanization. Group Processes \& Intergroup Relations, 14(1), 113-126. https:// doi.org/10.1177/1368430210370042.

Lane, I. M., \& Coon, R. C. (1972). Reward allocation in preschool children. Child Development, 43(4), 1382-1389. https://doi.org/10. 1111/j.1467-8624.1972.tb02092.x.

Leinbach, M. D., Hort, B. E., \& Fagot, B. I. (1997). Bears are for boys: Metaphorical associations in young children's gender stereotypes. Cognitive Development, 12(1), 107-130. https://doi.org/10.1016/ s0885-2014(97)90032-0.

Levy, G. D., Taylor, M. G., \& Gelman, S. A. (1995). Traditional and evaluative aspects of flexibility in gender roles, social conventions, moral rules, and physical laws. Child Development, 66(2), 515-531. https://doi.org/10.1111/j.1467-8624.1995.tb00887.x.

Liben, L. S., Bigler, R. S., \& Krogh, H. R. (2001). Pink and blue collar jobs: Children's judgments of job status and job aspirations in 
relation to sex of worker. Journal of Experimental Child Psychology, 79(4), 346-363. https://doi.org/10.1006/jecp.2000. 2611.

LoBue, V., \& DeLoache, J. S. (2011). Pretty in pink: The early development of gender-stereotyped colour preferences. British Journal of Developmental Psychology, 29(3), 656-667. https://doi.org/10. 1111/j.2044-835X.2011.02027.x.

LoBue, V., Nishida, T., Chiong, C., DeLoache, J. S., \& Haidt, J. (2011). When getting something good is bad: Even three-year-olds react to inequality. Social Development, 20(1), 154-170. https://doi.org/10. 1111/j.1467-9507.2009.00560.x.

Lourenco, S. F., Bonny, J. W., \& Schwartz, B. L. (2016). Children and adults use physical size and numerical alliances in third-party judgments of dominance. Frontiers in Psychology, 6, 2050-2060. https://doi.org/10.3389/fpsyg.2015.02050.

Lukaszewski, A. W., Simmons, Z. L., Anderson, C., \& Roney, J. R. (2016). The role of physical formidability in human social status allocation. Journal of Personality and Social Psychology, 110(3), 385-406. https://doi.org/10.1037/pspi0000042.

Ma, L., \& Woolley, J. D. (2013). Young children's sensitivity to speaker gender when learning from others. Journal of Cognition and Development, 14(1), 100-119. https://doi.org/10.1080/15248372. 2011.638687.

Maccoby, E. E., \& Jacklin, C. N. (1987). Gender segregation in childhood. Advances in Child Development and Behavior, 20, 239287. https://doi.org/10.1016/s0065-2407(08)60404-8 .

Mandalaywala, T. M., Rhodes, M., \& Tai, C. (2019). Children's use of race and gender as cues to social status. https://doi.org/10.31234/osf. io/3rnej.

Mansour, Z., \& Karam, S. (2012). School-related gender based violence (SRGBV) in Lebanon. Beirut. UNESCO Regional Bureau for Education in the Arab States. https://unesdoc.unesco.org/ark:/ 48223/pf0000219623.

Martin, C. L., \& Halverson Jr., C. F. (1981). A schematic processing model of sex typing and stereotyping in children. Child Development, 52(4), 1119-1134. https://doi.org/10.2307/1129498.

Martin, C. L., Ruble, D. N., \& Szkrybalo, J. (2002). Cognitive theories of early gender development. Psychological Bulletin, 128(6), 903933. https://doi.org/10.1037/0033-2909.128.6.903.

Martin, C. L., Andrews, N. C., England, D. E., Zosuls, K., \& Ruble, D. N. (2017). A dual identity approach for conceptualizing and measuring children's gender identity. Child Development, 88(1), 167-182. https://doi.org/10.1111/cdev.12568.

Mascaro, O., \& Csibra, G. (2012). Representation of stable social dominance relations by human infants. Proceedings of the National Academy of Sciences, 109(18), 6862-6867. https://doi.org/10. 1073/pnas.1113194109.

Murdock, G. P., \& Provost, C. (1973). Factors in the division of labor by sex: A cross-cultural analysis. Ethnology, 12(2), 203-225. https:// doi.org/10.2307/3773347.

Neff, K. D., Cooper, C. E., \& Woodruff, A. L. (2007). Children's and adolescents' developing perceptions of gender inequality. Social Development, 16(4), 682-699. https://doi.org/10.1111/j.1467-9507. 2007.00411.x.

Nelson, A. (2005). Children's toy collections in Sweden-A less gendertyped country? Sex Roles, 52(1-2), 93-102. https://doi.org/10.1007/ s11199-005-1196-5.

Olson, K. R., Shutts, K., Kinzler, K. D., \& Weisman, K. G. (2012). Children associate racial groups with wealth: Evidence from South Africa. Child Development, 83(6), 1884-1899. https://doi.org/10. 1111/j.1467-8624.2012.01819.x.

Omark, D. R., \& Edelman, M. S. (1975). A comparison of status hierarchies in young children: An ethological approach. Social Science Information, 14(5), 87-107. https://doi.org/10.1177/ 053901847501400505 .
Omark, D. R., Strayer, F. F., \& Freedman, D. G. (1980). Dominance relations: An ethological view of human conflict and social interaction. New York: Garland.

Ostrov, J. M., \& Keating, C. F. (2004). Gender differences in preschool aggression during free play and structured interactions: An observational study. Social Development, 13(2), 255-277. https://doi.org/ 10.1111/j.1467-9507.2004.000266.x.

Over, H., \& Carpenter, M. (2015). Children infer affiliative and status relations from watching others imitate. Developmental Science, 18(6), 917-925. https://doi.org/10.1111/desc.12275.

Parker, R., Wellings, K., \& Lazarus, J. V. (2009). Sexuality education in Europe: An overview of current policies. Sex Education, 9(3), 227242. https://doi.org/10.1080/14681810903059060.

Picariello, M. L., Greenberg, D. N., \& Pillemer, D. B. (1990). Children's sex-related stereotyping of colors. Child Development, 61(5), 14531460. https://doi.org/10.2307/1130755.

Pickert, S. M., \& Wall, S. M. (1981). An investigation of children's perceptions of dominance relations. Perceptual and Motor Skills, 52(1), 75-81. https://doi.org/10.2466/pms.1981.52.1.75.

Pun, A., Birch, S. A., \& Baron, A. S. (2016). Infants use relative numerical group size to infer social dominance. Proceedings of the National Academy of Sciences, 113(9), 2376-2381. https://doi.org/ 10.1073/pnas.1514879113.

Puts, D. A., Gaulin, S. J. C., \& Verdolini, K. (2006). Dominance and the evolution of sexual dimorphism in human voice pitch. Evolution and Human Behavior, 27(4), 283-296. https://doi.org/10.1016/j. evolhumbehav.2005.11.003.

Ridgeway, C. L. (2011). Framed by gender: How gender inequality persists in the modern world. Oxford: Oxford University Press.

Ridgeway, C. L. (2013). Gender, interaction, and inequality. New York: Springer Science \& Business Media.

Rochat, P., Dias, M. D., Liping, G., Broesch, T., Passos-Ferreira, C., Winning, A., ... Berg, B. (2009). Fairness in distributive justice by 3-and 5-year-olds across seven cultures. Journal of Cross-Cultural Psychology, 40(3), 416-442. https://doi.org/10.1177/ 0022022109332844

Rosaldo, M. Z., Lamphere, L., \& Bamberger, J. (1974). Woman, culture, and society. Stanford: Stanford University Press.

Rossholt, N. (2003). Barnehagen og førskolelarerutdanningen $i$ et kjønns-, likestillings- og diskursperspektiv [Kindergartens and early childhood education in a gender, equality and discourse perspective]. Oslo: Høgskolen i Oslo.

Schmid-Mast, M., \& Hall, J. A. (2004). Who is the boss and who is not? Accuracy of judging status. Journal of Nonverbal Behavior, 28(3), 145-165. https://doi.org/10.1023/b:jonb.0000039647.94190.21.

Sebanc, A. M., Pierce, S. L., Cheatham, C. L., \& Gunnar, M. R. (2003). Gendered social worlds in preschool: Dominance, peer acceptance and assertive social skills in boys' and girls' peer groups. Social Development, 12(1), 91-106. https://doi.org/10.1111/1467-9507. 00223.

Selten, R., \& Ockenfels, A. (1998). An experimental solidarity game. Journal of Economic Behavior \& Organization, 34(4), 517-539. https://doi.org/10.1016/s0167-2681(97)00107-8.

Shaw, A., \& Olson, K. R. (2012). Children discard a resource to avoid inequity. Journal of Experimental Psychology: General, 141(2), 382-395. https://doi.org/10.1037/e519402009-001.

Shutts, K., Banaji, M. R., \& Spelke, E. S. (2009). Social categories guide young children's preferences for novel objects. Developmental Science, 13(4), 599-610. https://doi.org/10.1111/j.1467-7687.2009. 00913.x.

Shutts, K., Kenward, B., Falk, H., Ivegran, A., \& Fawcett, C. (2017). Early preschool environments and gender: Effects of gender pedagogy in Sweden. Journal of Experimental Child Psychology, 162, 1-17. https://doi.org/10.31219/osf.io/8wj2p. 
Sluckin, A. M., \& Smith, P. K. (1977). Two approaches to the concept of dominance in preschool children. Child Development, 48(3), 917 923. https://doi.org/10.2307/1128341.

Stipek, D., \& Iver, D. M. (1989). Developmental change in children's assessment of intellectual competence. Child Development, 60(3), 521-538. https://doi.org/10.1111/j.1467-8624.1989.tb02734.x.

Strayer, F. F., Chapeskie, T. R., \& Strayer, J. (1978). The perception of preschool social dominance. Aggressive Behavior, 4(2), 183-192. https://doi.org/10.1002/1098-2337(1978)4:2\%3C183::aidab2480040209\%3E3.0.co;2-g.

Tabet, P. (1979). Les Mains, les outils, les armes [Hands, Tools, Weapons]. L'Homme, 19(3/4), 5-61. https://doi.org/10.3406/hom. 1979.367998

Tajfel, H., \& Turner, J. C. (1979). An integrative theory of intergroup conflict. In W. G. Austin \& S. Worchel (Eds.), Organizational identity: A reader (pp. 56-65). Chicago: Nelson-Hall.

Taylor, S. E., \& Brown, J. D. (1988). Illusion and well-being: A social psychological perspective on mental health. Psychological Bulletin, 103(2), 193-210. https://doi.org/10.1037/0033-2909.103.2.193.

Taylor, S. E., \& Brown, J. D. (1994). Positive illusions and well-being revisited: Separating fact from fiction. Psychological Bulletin, 116(1), 21-27. https://doi.org/10.1037/0033-2909.116.1.21.

Taylor, M. G., Rhodes, M., \& Gelman, S. A. (2009). Boys will be boys; cows will be cows: Children's essentialist reasoning about gender categories and animal species. Child Development, 80(2), 461-481. https://doi.org/10.1111/j.1467-8624.2009.01272.x.

Terrier, N., Bernard, S., Mercier, H., \& Clément, F. (2016). Visual access trumps gender in 3- and 4-year-old children's endorsement of testimony. Journal of Experimental Child Psychology, 146, 223-230. https://doi.org/10.1016/j.jecp.2016.02.002.

Terrizzi, B. F., Brey, E., Shutts, K., \& Beier, J. S. (2018). Children's developing judgments about the physical manifestations of power. Developmental Psychology, 55(4), 793-808. https://doi.org/10. 31234/osf.io/z75nu.

Terrizzi, B. F., Woodward, A. M., \& Beier, J. S. (2019). Young children and adults associate social power with indifference to others' needs. Advance online publication. https://doi.org/10.31234/osf.io/45uca.

Thomas, A. J., Thomsen, L., Lukowski, A. F., Abramyan, M., \& Sarnecka, B. W. (2018). Toddlers prefer those who win but not when they win by force. Nature Human Behaviour, 2(9), 662-669. https:// doi.org/10.1038/s41562-018-0415-3.

Thomsen, L., Frankenhuis, W. E., Ingold-Smith, M., \& Carey, S. (2011). Big and mighty: Preverbal infants mentally represent social dominance. Science, 331(6016), 477-480. https://doi.org/10.1126/ science. 1199198.

Todorov, A., Olivola, C. Y., Dotsch, R., \& Mende-Siedlecki, P. (2015). Social attributions from faces: Determinants, consequences, accuracy, and functional significance. Annual Review of Psychology, 66, 519-545. https://doi.org/10.1146/annurev-psych113011-143831.

Toscano, H., Schubert, T. W., \& Sell, A. N. (2014). Judgments of dominance from the face track physical strength. Evolutionary Psychology, 12(1), 1-18. https://doi.org/10.1177/ 147470491401200101.

Turner, P. J., Gervai, J., \& Hinde, R. A. (1993). Gender-typing in young children: Preferences, behaviour and cultural differences. British Journal of Developmental Psychology, 11(4), 323-342. https://doi. org/10.1111/j.2044-835x.1993.tb00607.x.

Weisfeld, G. E., \& Beresford, J. M. (1982). Erectness of posture as an indicator of dominance or success in humans. Motivation and Emotion, 6(2), 113-131. https://doi.org/10.1007/bf00992459.

Weisgram, E. S., Bigler, R. S., \& Liben, L. S. (2010). Gender, values, and occupational interests among children, adolescents, and adults. Child Development, 81(3), 778-796. https://doi.org/10.1111/j. 1467-8624.2010.01433.x.

Weisgram, E. S., Fulcher, M., \& Dinella, L. M. (2014). Pink gives girls permission: Exploring the roles of explicit gender labels and gendertyped colors on preschool children's toy preferences. Journal of Applied Developmental Psychology, 35(5), 401-409. https://doi. org/10.1016/j.appdev.2014.06.004.

West, C., \& Zimmerman, D. H. (1987). Doing gender. Gender \& Society, 1(2), 125-151 10.1177\%2F0891243287001002002.

Whyte, M. K. (1978). The status of women in preindustrial societies. Princeton: Princeton University Press. https://doi.org/10.1515/ 9781400871810-001.

Williams, J. E., \& Best, D. L. (1982). Measuring sex stereotypes. A thirtynation study. Beverly Hills: Sage.

Williams, J. E., Bennett, S. M., \& Best, D. L. (1975). Awareness and expression of sex stereotypes in young children. Developmental Psychology, 11(5), 635-642. https://doi.org/10.1037/0012-1649.11. 5.635.

Yavorsky, J. E., Dush, C. M. K., \& Schoppe-Sullivan, S. J. (2015). The production of inequality: The gender division of labor across the transition to parenthood. Journal of Marriage and Family, 77(3), 662-679. https://doi.org/10.1111/jomf.12189.

Yee, M., \& Brown, R. (1994). The development of gender differentiation in young children. British Journal of Social Psychology, 33(2), 183196. https://doi.org/10.1111/j.2044-8309.1994.tb01017.x.

Zammuner, V. L. (1982). Sex role stereotypes in Italian children. International Journal of Psychology, 17(1-4), 43-63. https://doi. org/10.1080/00207598208247431.

Publisher's Note Springer Nature remains neutral with regard to jurisdictional claims in published maps and institutional affiliations. 